\title{
O STF E A CONSTRUÇÃO INSTITUCIONAL DAS AUTORIDADES REGULADORAS DO SISTEMA FINANCEIRO: UM ESTUDO DE CASO DAS ADINS
}

Camila Duran-Ferreira

THE BRAZILIAN SUPREME COURT AND THE INSTITUTIONAL DESIGN OF THE PUBLIC AUTHORITIES OF THE NATIONAL FINANCIAL SYSTEM

\section{RESUMO}

Este artigo pretende aValiar a atuaç̃o da corte CONSTITUCIONAL BRASILEIRA, O SUPREMO TRIBUNAL FEDERAL, COMO VERDADEIRO ATOR NO DESENHO INSTITUCIONAL DAS AUTORIDADES REGULADORAS DO SISTEMA FINANCEIRO NACIONAL, O CONSELHO Monetário Nacional (CMN) e o Banco Central do Brasil. (BCB). SUA INTERAÇ̃̃O COM OS PODERES POLITICOS, POR MEIO DO JULGAMENTO DE AC̄̃̃ES DIRETAS DE INCONSTITUCIONALIDADE (ADINS), AO LONGO DOS ÚLTIMOS 20 ANOS, FORNECEU BALIZAS JURÍDICAS PARA. A CONSTRUÇÃO DESSAS AUTORIDADES. ESTA PESQUISA, QUE PARTE DE UMA ANÁLISE QUALITATIVA DAS DECISÕES DO TRIBUNAL COMO ESTUDO DE CASO, MAPEOU OS TEMAS E ATORES INTERESSADOS NA REGULAÇ̃O DO SISTEMA FINANCEIRO E NA ESTRUTURA DESSAS ENTIDADES, ASSIM COMO PROCUROU DEMONSTRAR COMO A ATUAÇÃO DA CORTE REFORÇOU A COMPETÊNCIA NORMATIVA DESSES ÓRGÄOS. AO FINAL, ESTE ARTIGO DELINEIA PARÂMETROS PARA EVENTUAL EDIÇĀO DE FUTURA LEGISLAÇ̃̃O, QUE VISE REGULAR O SISTEMA FINANCEIRO, REVOGANDO A LEI 4594 DE 1964, E CONCEDER EVENTUAL AUTONOMIA AO BANCO CENTRAL DO BRASIL.

\section{PALAVRAS-CHAVE}

SuPREMo TRIBUnal Federal; Controle de CONSTITUCIONALIDADE; ADIN, SISTEMA FINANCEIRO NACIONAL.

\section{ABSTRACT}

THE PURPOSE OF THIS STUDY IS TO ANALYSE THE MANNER THE BRAZILIAN SUPREME COURT'S (SUPREMO TRIBUNAL FEDERAL - STFI DECISIONS HAVE INFLUENCED THE INSTITUTIONAL DESIGN OF THE NATIONAL MONETARY COUNCIL AND THE BRAZILIAN CENTRAL BANK. DURING THE LAST 20 YEARS. STF PROVIDED LIMITS TO THE POWER OF THESE PUBLIC AUTHORITIES, BY JUDGING DIRECT ACTIONS OF UNCONSTITUTIONALITY (ADINS). THIS RESEARCH IS BASED ON EMPIRICAL STUDY THAT INTENDS TO IDENTIFY THE ACTORS AND THE ISSUES SUBMITTED TO THE COURT AND HOW ITS DECISION ENFORCED THEIR POWER OF REGULATING THE FINANCIAL SYSTEM. AS A RESULT, IT IS POSSIBLE TO PERCEIVE DIRECTIONS TO ENACT THE LAW THAT INTENDS TO REGULATE THE FINANCIAL SYSTEM AND EVENTUALLY TO ATTRIBUTE THE INDEPENDENCE TO THE BRAZILIAN CENTRAL BANK.

\section{KEYWORDS}

Brazilian Supreme Court (SuPREmo Tribunal FEDERAL): JUDICIAL REVIEW; DIRECT ACTION OF UNCONSTITUTIONALITY; NATIONAL FINANCIAL SYSTEM.

\section{INTRODUÇÃO}

O presente artigo tem o intuito de demonstrar como se desenvolve a relação institucional entre a Corte constitucional brasileira e as autoridades responsáveis pela regulação do Sistema Financeiro Nacional, em especial, o Conselho Monetário Nacional (CMN) e o Banco Central do Brasil (BCB). Por meio da análise do julgamento de ações diretas de inconstitucionalidade (ADIns), busca-se extrair uma 
orientação jurídica do Supremo Tribunal Federal (STF) para a (re)construção das autoridades reguladoras referidas. A investigação dessa relação justifica-se, portanto, pelo momento histórico em que se (re)pensa a estruturação do arcabouço normativo das agências e, especialmente, em relação ao mercado financeiro, ainda se espera, depois de 20 anos, a regulamentação do artigo 192 da Constituição Federal por lei complementar, e uma discussão jurídica legislativa sobre uma possível autonomia para o Banco Central do Brasil. ${ }^{1}$

Desde 1991, esse tema já era debatido no STF. Sydney Sanches, então ministro do tribunal, no julgamento da ADIn n. 4, declarava que:

Nem se há de imaginar, como argumento ad terrorem, que o Congresso

Nacional deixa, para o todo o sempre, de votar a lei complementar que deve regular o sistema financeiro nacional, por não lhe emprestar importância alguma na vida econômica do país. E se isso acontecer, não será por culpa do Poder Judiciário (ADIn 4, p. 806).

No presente, não se pode negar a preocupação do Congresso Nacional com o sistema financeiro do País, até mesmo porque ele tem participado de sua construção continuamente. ${ }^{2}$ É também evidente que a não promulgação da referida lei não pode ser atribuída ao Judiciário. Contudo, ela pode ser elaborada com a sua contribuição. Várias foram as ações diretas de inconstitucionalidade em que se discutiu nos últimos anos o conflito da normatização do sistema financeiro com a Constituição Federal. Várias foram, portanto, as situações de insegurança jurídica a respeito das normas emanadas pelas autoridades reguladoras, que foram solucionadas por respostas dadas pelo STF.

Assim, propõe-se, por meio da análise das decisões desse tribunal, dar uma baliza jurídica para a (re)construção dessas entidades, na medida em que é essa a instituição responsável por declarar o que é ou não constitucional numa estruturação do Estado político-econômico brasileiro. Muito além do que identificar os possíveis pontos de veto do Poder Judiciário a um projeto para o desenho das agências reguladoras, será possível também, por meio deste artigo, identificar quem são os atores políticos interessados e planejar uma estratégia que concilie os diversos interesses e temas presentes.

\section{i O debate no Supremo Tribunal Federal}

O STF é um ator extremamente relevante na arquitetura das instituições políticas, afinal, é ele o responsável pela revisão dos atos do Poder Executivo e do Congresso Nacional. Dessa forma, faz-se necessária uma reflexão sobre o funcionamento dessa instituição judiciária, que desempenha um papel importante no processo legislativo, 
e tem sido utilizada como um espaço de contestação por diversos atores sociais para impedir ou modificar o desenho de programas públicos, além da própria estruturação de entidades. Esse locus institucional oferece um mecanismo para que grupos de interesse possam expressar suas preferências que, de outro modo, seja no Legislativo ou no Executivo, não teriam instrumentos ou configuração de uma maioria. ${ }^{3}$

Às cortes judiciárias é atribuída a função de aferir a legitimidade constitucional da condução de uma política econômica, cabendo a elas avaliar a correspondência entre sua implementação e o alcance dos objetivos previamente definidos no plano político, por normas jurídicas formuladas pelos poderes Executivo e Legislativo. ${ }^{4}$ Ao interagir com esse sistema, ela o modifica e cria uma nova política, atuando como verdadeiro ator.

À expansão da atuação dos tribunais e à consequente transferência da decisão política sobre direitos do Legislativo e do Executivo para as cortes, é atribuída a ideia de judicialização da política ou expansão do poder judicial (TATE, 1995, p. 28). Diversas foram as condições que facilitaram o surgimento desse fenômeno: (1) a adoção de um governo democrático como regime político; (2) o sistema de separação de poderes e a adoção do mecanismo de judicial review (SHAPIRO; SWEET, 2002, p. 142); ${ }^{5}$ (3) a nova legitimação dos governos pela constitucionalização de direitos sociais e econômicos; (4) o uso das cortes por grupos de interesse e oposição política com objetivo de provocar a concretização ou modificação de programas públicos; (5) a ineficácia dos poderes Executivo e Legislativo para implementar políticas (Tate, 1995, p. 28-32); (6) e, especialmente, em relação ao sistema jurídico brasileiro, a proibição do "non liquet", ${ }^{6}$ que torna obrigatório um posicionamento da Corte sobre a questão levada à sua apreciação.

Após o processo brasileiro de redemocratização, a tradução de questões de política em questões de justiça foi acentuada pela previsão de preceitos para a atuação do Estado no ambiente socioeconômico, assim como pela incorporação de mecanismos especiais de controle de constitucionalidade. O ente estatal, ao selecionar políticas públicas que iriam constar de sua agenda e dar publicidade a suas decisões, vinculou expectativas e comportamentos dos grupos sociais beneficiados, traduzindo em normas jurídicas suas decisões políticas (FARIA, 1992). Dessa forma, a nova linguagem e os novos procedimentos do direito levaram o Poder Judiciário ao desempenho de um novo papel, "única instância institucional especializada em interpretar normas e arbitrar sobre sua legalidade e aplicação, especialmente nos casos sujeitos à controvérsia" (VIANNA, 1999, p. 20). Houve, portanto, um deslocamento do espaço público deliberativo, pensado tradicionalmente no exercício dos poderes políticos pelo Executivo e pelo Legislativo, para o Poder Judiciário, o qual se transformou em uma arena para a canalização da manifestação dos interesses desses atores.

Como pensar, então, o papel do Judiciário nesse contexto? Especialmente, em relação à Corte constitucional, esse estudo tem como objetivo demonstrar a importância do STF na construção das instituições públicas. Os grupos de interesse que 
não têm atendidas suas demandas nos poderes políticos continuam o debate nesse tribunal, por meio dos instrumentos oferecidos pela Constituição Federal de 1988 para o controle de constitucionalidade dos atos normativos. ${ }^{7}$

Nesse sentido, o STF foi chamado inúmeras vezes para se posicionar sobre a constitucionalidade de normas jurídicas no âmbito do sistema financeiro. $\mathrm{O}$ foco deste trabalho é o controle de constitucionalidade concentrado e, em especial, o estudo das ADIns $;^{8}$ ou seja, a fiscalização abstrata do STF exercida diretamente sobre atos normativos emanados pelos poderes políticos, sem um caso concreto subjacente à análise. ${ }^{9}$ Esse enfoque foi escolhido por algumas razões: (1) pelo efeito vinculante e a extensão da decisão de uma ADIn (essas deliberações estendem-se a todos, indistintamente, e não somente às partes processuais, ${ }^{10}$ além disso, têm efeito vinculante, relativamente aos demais órgãos do Poder Judiciário, administração pública direta ou indireta, em todas esferas da Federação); ${ }^{11}$ (2) por exigir uma decisão diretamente na Corte especial, órgão máximo responsável por essa modalidade de controle, sem a necessidade de percorrer todas as instâncias do Poder Judiciário, canalizando o problema político rapidamente na justiça constitucional; (3) e pela repercussão e visibilidade da decisão, no âmbito político e social.

Por outro lado, reconhece-se que o CMN e o BCB são também autoridades monetárias. Nesse sentido, excluiu-se da pesquisa as decisões do STF que, de algum modo, interferiram no exercício do poder especificamente monetário desses órgãos. ${ }^{12}$ Esse recorte metodológico, por vezes, apresenta-se frágil, uma vez que há uma fronteira tênue entre a disciplina monetária e a regulação sistêmica do sistema financeiro, mas se procurou respeitar os limites impostos por um breve artigo como este. Assim, serão analisadas decisões que interferiram exclusivamente nas competências exercidas pelo $\mathrm{CMN}$ e $\mathrm{BCB}$ como autoridades reguladoras, ou seja, no exercício da regulação prudencial, sistêmica e fiscalizadora sobre as instituições financeiras. ${ }^{13}$ Também serão analisadas as decisões relacionadas ao desenho institucional dessas autoridades, como aquelas em que se busca definir a natureza jurídica da entidade, e que determinam a constitucionalidade ou não de uma alteração da composição do órgão.

\section{UM ESTUDO DE CASO: O STF E AS AUTORIDADES REGULADORAS DO SISTEMA FINANCEIRO}

\section{I Metodologia}

Construiu-se análise qualitativa ${ }^{14}$ das deliberações do STF, em ações diretas de inconstitucionalidade, em que os órgãos de regulação do mercado financeiro - especificamente, o CMN e o $\mathrm{BCB}$-, tiveram sua regulamentação do setor contestada (ou a previsão legal dessa), assim como, decisões que discutiram a alteração do desenho da instituição, por decisão dos Poderes Executivo ou Legislativo. 
O resultado da análise dos dados é apresentado a partir de uma perspectiva qualitativa, isto é, identificando o fundamento e a decisão do tribunal para dar resposta jurídica ao problema submetido ao seu controle. Assim, construiu-se um modelo de análise jurisprudencial para aplicação em cada caso, no intuito de identificar as questões debatidas e as razões jurídicas formuladas pelos julgadores.

ÓRGÃO JULGADOR: STF - PLENO OU DECISÃO MONOCRÁTICA 15

FONTE: IDENTIFICACÃO DA LOCALIZACÃO DO ACÓRDÃO - REVISTA (NÚMERO E PÁGINA INICIAL) OU ENDEREÇO ELETRÔNICO

CASO: DESIGNAC̣ÃO DE UM NOME PARA O CASO ANALISADO

CLASSE E NÚMERO: CLASSE PROCESSUAL E NÚMERO DE IDENTIFICAC̣ÃO

RELATOR: DESIGNAÇÃO DO JULGADOR QUE DESENVOLVEU O RELATO DO PROCESSO 16

DATA DO JULGAMENTO: DIA, MÊS E ANO DA DECISÃO PELO TRIBUNAL (DD/MM/AAAA)

DATA DA PUBLICAÇÃO: DIA, MÊS E ANO DA PUBLICAÇÃO DA DECISÃO NO DIÁRIO OFICIAL DA UNIÃO

(DD/MM/AAAA)

PARTES: DESIGNAÇÃO DAS PARTES QUE FIGURARAM NA RELAÇÃO PROCESSUAL; IDENTIFICAÇÃO DOS ATORES QUE RECORRERAM AO ESPACุO JUDICIAL PARA QUESTIONAR AS POLÍTICAS ECONÔMICAS NO ÂMBITO DO SISTEMA FINANCEIRO NACIONAL

DISPOSITIVO(S) QUESTIONADO(S): TRANSCRIÇÃO DOS DISPOSITIVOS NORMATIVOS ABORDADOS PELA DECISÃO E QUE CONSTITUÍRAM O FUNDAMENTO PRINCIPAL DO ACÓRDÃO

FATOS: BREVE HISTÓRICO MATERIAL E PROCESSUAL DO CASO

QUESTÕES RELEVANTES: INDAGAÇÕES RELEVANTES PARA O TEMA ESTUDADO, QUE SERÃO ILUSTRADAS OU RESPONDIDAS PELO CASO

FUNDAMENTO PRINCIPAL: RACIOCÍNIO DESENVOLVIDO PELO JULGADOR E DIRIGIDO À QUESTÃO ILUSTRADA PELO CASO

DECISÃO: DELIBERACÃO TOMADA NO CASO ANALISADO; IDENTIFICAÇ̃̃O DO POSICIONAMENTO DO TRIBUNAL E RELAÇÃO DOS MINISTROS QUE VOTARAM NO MESMO SENTIDO

VOTO VENCIDO: REGISTRO DE QUEM PROFERIU VOTO DIVERGENTE

FUNDAMENTO DO VOTO VENCIDO: RACIOCÍNIO DESENVOLVIDO PELO JULGADOR, QUE DIVERGIU DA DECISÃO DA MAIORIA; SEU REGISTRO É ORIENTADO TAMBÉM PELA QUESTÃO ILUSTRADA PELO CASO

PRECEDENTE(S): CASOS ANTERIORES CITADOS PELOS MINISTROS NO MESMO SENTIDO DA DECISÃO ANALISADA

\subsection{ANÁlise do CASO: ATORES POLÍTICOS E TEMPO PROCESSUAL}

Foram encontradas 23 decisões ${ }^{17}$ em 14 ADIns (denominadas de "casos", nesta pesquisa), ${ }^{18}$ que discutiram dois temas diferentes abrangidos pela proposta do artigo. São eles: desenho institucional das autoridades reguladoras e competência normativa do $\mathrm{CMN}$ e do $\mathrm{BCB}$. Dessas decisões, 17 são deliberações do Pleno e 6 são monocráticas.

Os casos encontrados e analisados, classificados por ordem crescente do número do processo, foram os seguintes: 
072 : O STF E A CONSTRUÇÃO INSTITUCIONAL DAS AUTORIDADES REGULADORAS DO SISTEMA FINANCEIRO

\section{TABELA I}

Lista das ADIns analisadas por órgão julgador (STF: pleno ou decisão monocrática), ano do julgamento e lapso temporal entre julgamento da medida cautelar (ADIn MC) e decisão final (ADIn).*

\begin{tabular}{|c|c|c|c|c|c|}
\hline CASO & PLENO & ANO & $\begin{array}{l}\text { DECISÃO } \\
\text { MONOCRÁTICA }\end{array}$ & ANO & $\begin{array}{l}\text { LAPSO } \\
\text { TEMPORAL }\end{array}$ \\
\hline \multirow[t]{2}{*}{ 1. $\operatorname{ADIN} 4$} & - ADIN MC 4 & 1988 & & & 3 ANOS \\
\hline & - ADIN 4 & 1991 & & & \\
\hline 2. SOCIEDADES CORRETORAS & - ADIN 418 & 1990 & & & -1 \\
\hline 3. SERVIDORES DO BCB I & - ADIN 449 & 1996 & & & - \\
\hline 4. UDR & - ADIN MC 886 & 1993 & ADIN 886 & 2002 & 9 ANOS \\
\hline \multirow[t]{2}{*}{ 5. SERVIDORES DO BCB II } & - ADIN MC 1056 & 1994 & & & 3 ANOS \\
\hline & - ADIN 1056 & 1997 & & & \\
\hline 6. COOPERATIVA DE CRÉDITO & - ADIN MC 1277 & 1995 & & & SEM DECISÃO FINAL ${ }^{2}$ \\
\hline 7. COMPOSIÇÃO DO CMN & - ADIN MC 1312 & 1995 & ADIN 1312 & 2004 & 9 ANOS \\
\hline 8. BRB & - ADIN MC 1357 & 1995 & & & SEM DECISĀO FINAL \\
\hline 9. PROER & - ADIN MC 1376 & 1995 & ADIN 1376 & 2003 & 8 ANOS \\
\hline 10. FGC & - ADIN MC 1398 & 1996 & ADIN 1398 & 2003 & 7 ANOS \\
\hline 11. DEPÓSITO BANCÁRIO & - ADIN MC 1715 & 1998 & ADIN 1715 & 2005 & 7 ANOS \\
\hline 12. AUDITORIAS INDEPENDENTES & - ADIN MC 2317 & 2000 & ADIN 2317 & 2003 & 3 ANOS \\
\hline \multirow[t]{2}{*}{ 13. $\operatorname{CDC}$} & - ADIN 2591 & 2006 & & & - \\
\hline & - ADIN ED 32591 & 2006 & & & \\
\hline 14. PRESIDENTE DO BCB & - ADIN 3289/ 3290 & 2005 & & & - \\
\hline
\end{tabular}

* Dados da pesquisa.

1 A ADIn foi julgada diretamente, sem pedido pelo autor ou análise pelo STF de medida cautelar.

2 Sem decisão final, até a redação final deste artigo.

3 ADIn ED são embargos de declaração em ação direta de inconstitucionalidade. Cabe esse recurso contra decisão judicial que apresenta obscuridade, contradição ou omissão (artigo 535, Código de Processo Civil, Lei 5869/1973).

O tempo médio de espera entre o julgamento da medida cautelar ${ }^{19}$ e a decisão final é de, aproximadamente, 6,13 anos (excluindo-se do cálculo as ADIns que ainda não foram julgadas).

Das 14 ADIns analisadas, 6 foram iniciadas por partidos políticos de oposição ao governo da época, ${ }^{20} 3$ pelo Procurador Geral da República (PGR), 3 por entidades de $_{\text {classe }}{ }^{1}$ e 2 por governadores. ${ }^{22}$

A partir da análise do material empírico, foi possível observar que, na maioria dos casos, há dois tipos de decisão judicial: a primeira, em medida cautelar, e a segunda, em julgamento final. Assim, serão apresentadas duas respostas para a questão de quais 
atores foram atendidos pelo STF: a decisão dos ministros em medida cautelar e em decisão final, seja pela Plenária ou por decisão monocrática. ${ }^{23}$

TABela 2

Quem teve sua demanda atendida pelo STF?*

\begin{tabular}{|c|c|c|c|}
\hline CASO & $\begin{array}{l}\text { TEVE ATENDIDA SUA } \\
\text { DEMANDA PELO STF } \\
\text { AUTOR DA ADIN }\end{array}$ & $\begin{array}{l}\text { TEVE ATENDIDA SUA } \\
\text { DEMANDA PELO STF } \\
\text { EM MEDIDA CAUTELAR? }\end{array}$ & EM DECISÃO FINAL? \\
\hline 1. $A D I N 4$ & PARTIDO POLÍTICO & NÃO & NÃO \\
\hline 2. SOCIEDADES CORRETORAS & PGR & - & NÃO \\
\hline 3. SERVIDORES DO BCB I & PGR & - & $\mathrm{SIM}$ \\
\hline 4. UDR & ENTIDADE DE CLASSE & NÃO & AÇÃO PREJUDICADA \\
\hline 5. SERVIDORES DO BCB ॥ & PGR & $\mathrm{SIM}$ & AÇÃO PREJUDICADA \\
\hline 6. COOPERATIVA DE CRÉDITO & GOVERNADOR & NÃO & SEM DECISÃO FINAL \\
\hline 7. COMPOSIC̣ÃO DO CMN & PARTIDO POLÍTICO & NÃO & AÇÃO PREJUDICADA \\
\hline 8. BRB & GOVERNADOR & $\mathrm{SIM}$ & SEM DECISÃO FINAL \\
\hline 9. PROER & PARTIDO POLÍTICO & NÃO & AÇÃO PREJUDICADA \\
\hline 10. FGC & PARTIDO POLÍTICO & SIM, PARCIALMENTE & AÇÃO PREJUDICADA \\
\hline 11. DEPÓSITO BANCÁRIO & PARTIDO POLÍTICO & NÃO & AÇÃO PREJUDICADA \\
\hline 12. AUDITORIAS INDEPENDENTES & ENTIDADE DE CLASSE & NÃO & AÇÃO PREJUDICADA \\
\hline 13. $\mathrm{CDC}$ & ENTIDADE DE CLASSE & - & NÃO \\
\hline 14. PRESIDENTE DO BCB & PARTIDO POLÍTICO & - & NÃO \\
\hline
\end{tabular}

* Dados da pesquisa.

Em somente quatro dos casos analisados (2, 3, 13 e 14), o STF julgou diretamente a ação, sem passar pela análise da medida cautelar. Pela observação da Tabela 2 , verifica-se que o ator mais atendido pelo tribunal é o Ministério Público da União, por meio de seu representante, o Procurador-Geral da República. ${ }^{24}$ Das quatro decisões provocadas, duas foram atendidas e uma foi julgada prejudicada por motivos processuais. Somente houve resposta expressamente negativa em uma decisão. Os partidos políticos de oposição, por sua vez, estão entre os menos atendidos e os que mais procuraram um posicionamento da Corte. Eles receberam somente uma resposta positiva e, ainda, parcialmente. ${ }^{25}$ Além disso, tiveram negadas seis demandas e quatro foram julgadas prejudicadas por motivos processuais. Eles são seguidos pelas entidades de classe, que provocaram cinco decisões do tribunal, sendo três negadas e duas julgadas prejudicadas por motivo processual. Por seu turno, os governadores pediram quatro decisões ao STF, uma foi negada e a outra 
074 : O STF E A CONSTRUÇÃO INSTITUCIONAL DAS AUTORIDADES REGULADORAS DO SISTEMA FINANCEIRO

foi atendida. Entretanto, eles ainda esperam duas decisões finais da Corte, há mais de 12 anos.

Das sete ADIns julgadas prejudicadas por perda do objeto da ação, os fundamentos foram: (1) em três, alteração do ato normativo questionado; (2) em duas, alteração do parâmetro constitucional; ${ }^{26}$ (3) em uma, o não aditamento de procuração com poderes específicos para interposição de ação direta de inconstitucionalidade; (4) e, por fim, uma delas por perda da legitimidade da parte autora.

\subsection{Análise temática}

Neste item, serão analisadas as questões relevantes debatidas e as respostas dadas pelo Tribunal. O intuito é retirar uma orientação jurídica para uma futura alteração institucional das autoridades reguladoras.

\subsection{Desenho institucional Das autoridades Reguladoras}

Dentre os 14 casos selecionados, 4 referem-se especificamente ao desenho institucional dessas entidades. Eles discutem sua natureza jurídica e a de seus principais agentes, bem como a possibilidade de medida provisória ou lei ordinária disporem sobre alteração de sua composição ou regime jurídico do seu quadro de funcionários. Todas essas questões têm um pano de fundo: a exigência de lei complementar para disciplina do sistema financeiro nacional, conforme determinação do artigo 192 da Constituição Federal.

As ADIns analisadas compreendem o caso dos Servidores do BCB I e II, o caso da Composição do CMN e o caso do presidente do BCB. As questões relevantes, submetidas ao STF, foram as seguintes:

1. Qual é a natureza jurídica do $\mathrm{BCB}$ e dos integrantes de seu quadro de funcionários?

2. Pode portaria do BCB disciplinar plano de carreira de seus servidores?

3. Alteração da composição do CMN é matéria reservada à lei complementar?

4. Contraria o interesse público os dispositivos de medida provisória, posteriormente convertida em lei ordinária, que retiraram a participação de representantes da sociedade civil da composição do CMN?

5. Podem ser atribuídos ao presidente do $\mathrm{BCB}$ o status de ministro de Estado e, consequentemente, a prerrogativa de foro, por meio de medida provisória?

6. Qual é a natureza jurídica do presidente do BCB?

As respostas às questões formuladas estão na Tabela 3.

\section{TABela 3}

Decisão e fundamento do STF para questões relevantes sobre o desenho institucional das autoridades reguladoras. ${ }^{*}$ 


\begin{tabular}{|c|c|c|c|}
\hline CASO & $\begin{array}{l}\text { COMO O STF } \\
\text { DECIDIU? }\end{array}$ & $\begin{array}{l}\text { QUAIS FORAM OS FUNDAMENTOS } \\
\text { E A DECISÃO DO STF? }\end{array}$ & $\begin{array}{l}\text { O STF SUSPENDEU OS } \\
\text { EFEITOS DOS ATOS } \\
\text { NORMATIVOS CONTESTADOS? }\end{array}$ \\
\hline \multirow[t]{2}{*}{$\begin{array}{l}\text { 3. SERVIDORES } \\
\text { DO BCB I }\end{array}$} & $\begin{array}{l}\text { EM MEDIDA } \\
\text { CAUTELAR }\end{array}$ & $\begin{array}{l}\text { NÃO HOUVE JULGAMENTO DE MEDIDA. } \\
\text { CAUTELAR PELO TRIBUNAL }\end{array}$ & - \\
\hline & EM DECISÃO FINAL & 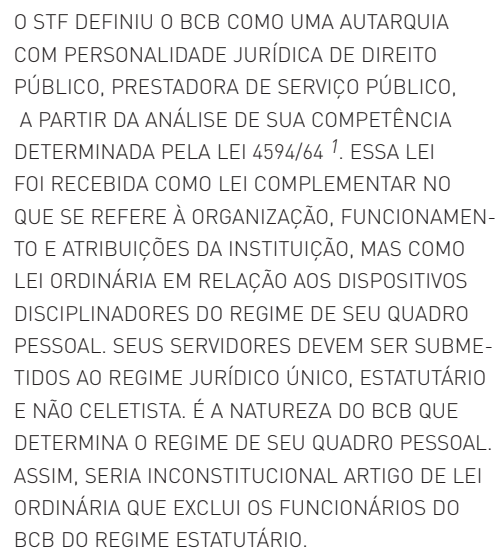 & SIM, POR UNANIMIDADE \\
\hline \multirow[t]{2}{*}{$\begin{array}{l}\text { 5. SERVIDORES } \\
\text { DO BCB II }\end{array}$} & $\begin{array}{l}\text { EM MEDIDA } \\
\text { CAUTELAR }\end{array}$ & $\begin{array}{l}\text { SEGUNDO O STF, PORTARIA DO BCB NÃO } \\
\text { PODERIA DISCIPLINAR PLANO DE CARREIRA } \\
\text { DO QUADRO PESSOAL DA ENTIDADE, } \\
\text { PORQUE CONFLITA COM A EXIGÊNCIA DE } \\
\text { CONCURSO PÚBLICO. }\end{array}$ & SIM, POR MAIORIA $(6 \times 2)$ \\
\hline & EM DECISÃO FINAL & $\begin{array}{l}\text { APÓS } 3 \text { ANOS, A ADIN FOI JULGADA } \\
\text { PREJUDICADA, PELO PLENÁRIO, DEVIDO AO } \\
\text { ADVENTO DA MEDIDA PROVISÓRIA, QUE } \\
\text { INCLUIU OS SERVIDORES DO BCB EM REGIME } \\
\text { JURÍDICO ÚNICO. ELA FOI EDITADA QUASE } 4 \\
\text { MESES APÓS O JULGAMENTO DO CASO DOS } \\
\text { SERVIDORES DO BCB I, EM } 1996 .\end{array}$ & - \\
\hline $\begin{array}{l}\text { 7. COMPOSIÇÃO } \\
\text { DO CMN }\end{array}$ & $\begin{array}{l}\text { EM MEDIDA } \\
\text { CAUTELAR }\end{array}$ & 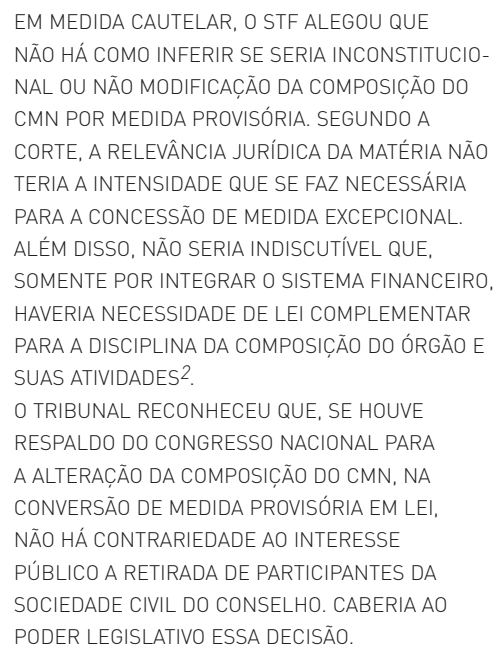 & NÃO, POR UNANIMIDADE \\
\hline
\end{tabular}


076 : O STF E A CONSTRUÇÃO INSTITUCIONAL DAS AUTORIDADES REGULADORAS DO SISTEMA FINANCEIRO

\begin{tabular}{|c|c|c|c|}
\hline & EM DECISÃO FINAL & $\begin{array}{l}\text { EM DECISÃO MONOCRÁTICA, QUASE } 9 \text { ANOS } \\
\text { DEPOIS, O STF JULGOU POR PERDA DO OBJETO } \\
\text { A ACCAAO, DEVIDO AO ADVENTO DA EMENDA } \\
\text { CONSTITUCIONAL 40/2003, QUE ALTEROU O } \\
\text { ARTIGO } 192 \text { DA CF. }\end{array}$ & - \\
\hline $\begin{array}{l}\text { 14. PRESIDENTE } \\
\text { DO BCB }\end{array}$ & $\begin{array}{l}\text { EM MEDIDA } \\
\text { CAUTELAR }\end{array}$ & $\begin{array}{l}\text { O STF JULGOU DIRETAMENTE A ACC̃̃O, SEM } \\
\text { ANÁLISE DA MEDIDA CAUTELAR. }\end{array}$ & - \\
\hline & EM DECISÃO FINAL & 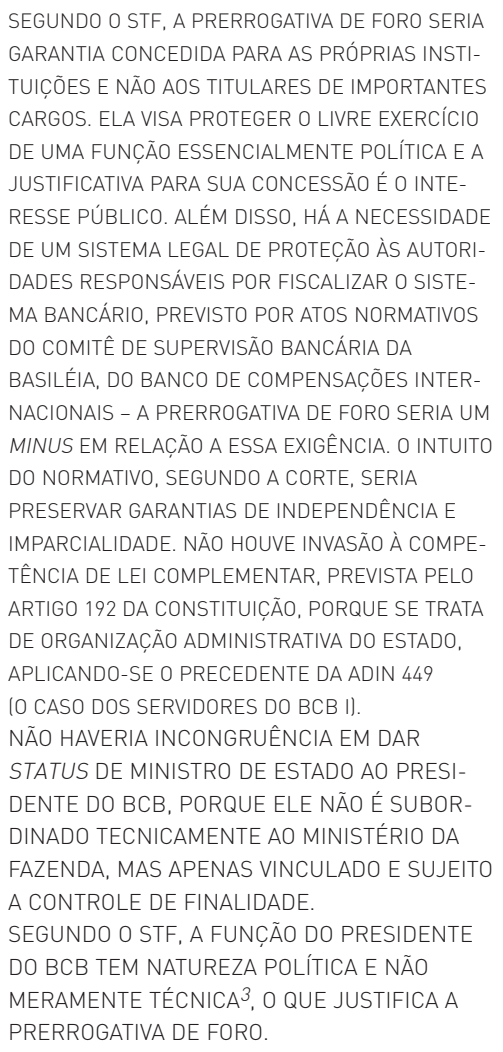 & NÃO, POR MAIORIA (6 X 4 ) \\
\hline
\end{tabular}

* Dados da pesquisa.

1 Nas palavras do STF o BCB é uma "autarquia que exerce, substancialmente, atividades públicas, assim prestadora de serviços públicos, pelo que é uma autêntica autarquia de personalidade jurídica de direito público” (ADIn 449, p. 432). 2 ADIn MC 1376, pp. 217 e 221.

$3 \mathrm{O}$ argumento do ministro relator Gilmar Mendes, nas ADIns 3289 e 3290, tem o mesmo sentido de Sola e outros (2002).

Pela análise da Tabela 3, observa-se que o STF respondeu às questões 2, 3 e 4 em medida cautelar, para, posteriormente, julgar pela perda do objeto da ação em decisão final. No entanto, a Corte já fornece alguns parâmetros: (1) não é evidente que, por ser o CMN uma instituição do sistema financeiro nacional, sua composição e atividades deveriam ser disciplinadas por lei complementar; ${ }^{27}$ (2) em um primeiro momento, o STF afirma que a discussão da matéria (composição 
do $\mathrm{CMN}$ ) não teria a relevância jurídica necessária para ter uma medida cautelar concedida, ${ }^{28}$ mas na decisão do caso do presidente do $\mathrm{BCB}$, ele ressalta continuamente a importância da entidade e traz para si o controle de seu principal agente,${ }^{29}$ o que pode revelar uma mudança da atitude da Corte: após 10 anos, ela se reconhece também como um agente responsável pela garantia do funcionamento do sistema financeiro; ${ }^{30}$ (3) e o respeito à decisão do Congresso Nacional é revelado por meio da fundamentação de que é ele o ente legitimado para dizer se contraria ou não interesse público a retirada da participação de representantes da sociedade civil da composição do CMN.

Além disso, nos casos dos servidores do BCB, houve uma interação institucional entre o Poder Executivo e a Corte. Após a decisão da ADIn 449, o presidente da República editou medida provisória para incluir os servidores do BCB no regime jurídico único. Isso demonstraria o respeito do Poder Executivo às decisões de constitucionalidade do STF; ou seja, o sistema brasileiro de checks and balances ${ }^{31}$ funcionou nesse caso.

Em relação à questão 1, o ministro relator Carlos Velloso definiu a natureza da entidade como autarquia prestadora de serviço público, a partir da análise de sua competência legal. Ocorre que o ministro Ilmar Galvão, que acompanhou o voto do relator, afirmou que "se, por efeito dos ventos liberalizantes que ora sopram no País, outro tipo de organização lhe vier a ser conferido pela lei complementar do art. 192, [...] essa lei complementar certamente ditará, se for o caso, o novo regime a que os empregados serão submetidos" (ADIn 449, p. 433). A questão é: poderia se definir regime diverso aos servidores, em futura lei complementar, a partir da fundamentação dada pelo ministro relator? O ministro Carlos Velloso ressaltou que, o que define o regime jurídico de servidores é a natureza jurídica da entidade. O voto do ministro Sepúlveda Pertence acrescentou que:

[...] o que define o Banco Central como autarquia não é o fato de Lei n. 4595 ter sido recebida pela Constituição; o Banco Central não poderia deixar de ser uma autarquia porque é instrumento de execução pela União de funções tipicamente estatais, de acordo com o art. 21, da Constituição, as quais nenhuma lei ordinária poderia confiar a entidades de direito privado, quais, as empresas públicas e mistas (ADIn 449, p. 436).

Assim, os ministros reforçam o argumento da natureza pública da entidade: ela não depende somente de competência estabelecida por lei, mas principalmente daquela determinada pela interpretação constitucional do STF. Entretanto, com o advento da Emenda Constitucional 19/1998, foi abolida a obrigatoriedade do regime jurídico único para a Administração Pública, permitindo a existência concomitante de cargos e empregos públicos, portanto, regime estatutário e celetista, respectivamente. 
Além disso, por previsão legal (Lei 9986/2000), adotou-se o regime celetista para as agências reguladoras, mesmo exercendo estas funções tipicamente estatais da União. Assim, tendo em vista essas alterações posteriores feitas pelo Congresso Nacional, nada impediria que fosse modificado o regime jurídico do quadro pessoal do BCB, por lei ordinária, após a alteração de sua natureza jurídica por futura lei complementar.

As respostas do STF às indagações 5 e 6, por sua vez, mostram também uma Corte preocupada com o uso do Judiciário como “tática de guerrilha” (ADIn 3289, p. 21). Toda a argumentação do ministro Gilmar Mendes, relator do caso presidente do BCB, buscou demonstrar a necessidade de um foro privilegiado para dar uma perspectiva de estabilidade à instituição, evitar a contestação de medidas de importantes agentes políticos em diferentes instâncias do Poder Judiciário e dar ao STF o privilégio do controle no centro do funcionamento do sistema de justiça. ${ }^{32}$ Apesar do CMN não ser mencionado por nenhum dos votos, tampouco o sistema de metas de inflação, o STF procurou nortear a relação entre o Ministério da Fazenda e o BCB. Trata-se de uma relação institucional de vinculação e não de subordinação, o que sujeita o BCB a um controle somente do cumprimento de finalidades.

Ainda, cabe ponderar que, no caso dos servidores do BCB, é afastado o argumento de que a disciplina do quadro de funcionários estaria compreendida no âmbito de lei complementar, prevista pelo artigo 192, por ser matéria de organização administrativa. No entanto, no caso do presidente do BCB, reforça-se constantemente o argumento de que o presidente não é agente meramente técnico, mas essencialmente político. Contudo, o STF aplica o precedente e diz novamente que é matéria de organização administrativa, passível de ser regulada por medida provisória. Entretanto, o ministro Carlos Velloso, que era relator do caso dos Servidores na época, é voto vencido na ADIn 3289. Segundo ele, o presidente do BCB é o "próprio sistema financeiro nacional” (p. 78), dependendo de regulamentação por lei complementar. Ainda, ele insere um debate sobre a independência do BCB no julgamento: "o que é relevante e deve ser discutido é se ao Banco Central deve ser concedida autonomia relativamente ao governo; não é simplesmente fazer do presidente do Banco Central Ministro de Estado, que continuará subordinado ao presidente da República" (ADIn 3289, p. 74). E, mais adiante, o ministro Marco Aurélio, pergunta: "a independência do Banco Central poderá ser tratada mediante medida provisória?”, ao que Carlos Velloso responde categoricamente: "tenho certeza que esta Corte não admitiria" (ADIn 3289, p. 79).

Dessa forma, por meio da análise desses casos, é possível deduzir que, ainda que o STF tenha dito, por maioria de votos, que a alteração da natureza jurídica do presidente do BCB é meramente administrativa, um projeto de lei ordinária ou medida provisória, que vise dar autonomia ao presidente e aos diretores do BCB, poderiam encontrar dificuldades ao passar pelo crivo da Corte. Além do placar ter sido "apertado" (6 contra 4 votos) ${ }^{33}$ e ainda que os ministros Sepúlveda Pertence e Carlos Velloso, vencidos, não estejam mais na Corte, essa estratégia política seria arriscada. Trata-se 
de matéria que está no foco do STF, nesse momento. ${ }^{34} \mathrm{O}$ julgamento direto da ADIn 3289, sem passar pelo pedido de medida cautelar, mostra como a Corte está interessada nesse domínio e, como se verá adiante no caso CDC, com a alteração de seu entendimento sobre a prejudicialidade da ação por alteração do parâmetro constitucional, ela não mais decide "não decidir" em julgamento final.

Dessa forma, uma sugestão é de que a reestruturação da entidade seja feita por lei complementar, com pedido de urgência, se o momento político o exigir. ${ }^{35}$ É evidente que aprovar uma lei complementar, desse teor, exige também condições políticas favoráveis no Congresso Nacional. No entanto, há um risco de que, se feita de outra forma, ela seja declarada inconstitucional pelo STF. Em relação ao quadro de servidores do $\mathrm{BCB}$, no entanto, não parece haver problemas em ser feita disciplina ou alteração por lei ordinária, desde que coerente com a natureza jurídica da entidade.

Por fim, uma última observação refere-se ao alto índice de discordância dos ministros no julgamento desse tema. Dentre 4 decisões tomadas pelo Pleno, em 2 houve divergências e, nelas, a decisão final foi deliberada pelo número mínimo de ministros necessários para julgar a constitucionalidade ou inconstitucionalidade de um ato normativo, ou seja, seis ministros.

\subsubsection{CompetênCia normativa do CMN e do BCB}

Esse tema foi o mais discutido pelo STF nas ações diretas de inconstitucionalidade selecionadas. Dentre os 14 casos, 10 referem-se à competência normativa do CMN e do BCB. São eles: o caso ADIn 4, o caso das Sociedades Corretoras, o caso UDR, o caso da Cooperativa de Crédito, o caso BRB, o caso Proer, o caso FGC, o caso do Depósito Bancário, o Caso dos Auditores Independentes e o caso CDC.

As questões submetidas ao STF relacionavam-se basicamente com a disciplina do sistema financeiro nacional e a exigência de lei complementar, conforme disposição do artigo 192 da Constituição Federal. As indagações, por vezes, não se referiam expressamente a atos normativos emanados pelas autoridades reguladoras, mas sim à constitucionalidade de previsão legal dessa competência, seja por medida provisória ou por lei ordinária. Esses casos foram selecionados porque, por vezes, o STF confirmava a atribuição de poderes às autoridades reguladoras por meio desses instrumentos, o que, na prática, ampliou sua possibilidade de intervenção no domínio econômico para disciplinar a matéria por resolução ou circular, sem previsão expressa pela Lei 4595/64, recebida pelo sistema jurídico como lei complementar disciplinadora do sistema financeiro nacional.

As questões foram as seguintes:

1. A limitação da taxa de juros reais em $12 \%$ ao ano, prevista pela redação anterior do artigo 192, aplica-se imediatamente às obrigações jurídicas, logo após a promulgação da Constituição Federal, em 1988? 36 $^{36}$ 
2. O Poder Executivo, por meio de resolução do CMN, pode reeditar texto de medida provisória rejeitada pelo Poder Legislativo, que disciplina a atividade de sociedades corretoras?

3. O BCB tem competência normativa, atribuída por lei ordinária, para disciplinar a remuneração, a atualização monetária e prazos mínimos de operações realizadas no mercado financeiro?

4. Pode lei estadual legislar de forma complementar sobre cooperativas de crédito? 5. Lei do Distrito Federal, que disciplina operações de empréstimo para servidores públicos em banco regional e exige depósito compulsório do governo do DF, invade competência privativa de lei complementar do sistema financeiro nacional? 6. Pode medida provisória disciplinar a constituição e o funcionamento de instituições financeiras, matéria reservada à lei complementar, conforme preceitua o artigo 192 da Constituição?

7. O CMN incidiu sobre domínio reservado à competência legislativa do Congresso Nacional, ao disciplinar o Fundo Garantidor de Crédito (FGC)?

8. Qual é a natureza jurídica do depósito bancário?

9. A disciplina do contrato de depósito bancário por resolução do CMN ofende o princípio da legalidade?

10. Pode resolução do CMN disciplinar atividade de auditorias independentes em instituição financeira?

11. O Código de Defesa do Consumidor (CDC) aplica-se à atividade de prestação de serviços por instituições financeiras?

12. Aplica-se o Código de Defesa do Consumidor (CDC) à fixação da taxa de juros por instituições financeiras?

\section{TABela 4}

Decisão e fundamento do STF para questões relevantes sobre a competência normativa do CMN e do BCB.*

\begin{tabular}{|c|c|c|c|}
\hline CASO & $\begin{array}{l}\text { COMO O STF } \\
\text { DECIDIU? }\end{array}$ & $\begin{array}{l}\text { QUAIS FORAM OS FUNDAMENTOS } \\
\text { E A DECISÃO DO STF? }\end{array}$ & $\begin{array}{l}\text { O STF SUSPENDEU OS EFEITOS } \\
\text { DOS ATOS NORMATIVOS } \\
\text { CONTESTADOS? }\end{array}$ \\
\hline 1. ADIN 4 & $\begin{array}{l}\text { EM MEDIDA } \\
\text { CAUTELAR }\end{array}$ & $\begin{array}{l}\text { PRIMEIRAMENTE, O STF AFIRMOU QUE NÃO HÁ } \\
\text { CONSENSO, EM DIREITO E ECONOMIA, NA } \\
\text { DEFINIÇÃO DE JUROS REAIS; E, NĀO HÁ NO } \\
\text { CASO O REQUISITO PARA CONCESSÃO DE } \\
\text { MEDIDA CAUTELAR, UMA VEZ QUE SERIA RÁPIDA } \\
\text { A TRAMITAÇÃO QUE AS ADINS COSTUMAM TER E, } \\
\text { ATÉ A DECISÃO FINAL, NADA OBSTARIA A CON- } \\
\text { TESTAÇĀO DE INCONSTITUCIONALIDADE, EM } \\
\text { QUALQUER INSTÂNCIA JUDICIAL, PELOS INTE- } \\
\text { RESSADOS NESSA QUESTÃO. DECIDIU NÃO } \\
\text { SUSPENDER OS EFEITOS DO PARECER DA } \\
\text { CONSULTORIA GERAL DA REPÚBLICA, QUE }\end{array}$ & NÃO, POR UNANIMIDADE \\
\hline
\end{tabular}


PREVIA A INAPLICABILIDADE IMEDIATA DO TABELAMENTO DE JUROS, E A CORRESPONDENTE CIRCULAR DO BCB (CIRCULAR 1365/88), QUE DETERMINOU ÀS INSTITUICOÕES FINANCEIRAS A OBSERVÂNCIA DA LEGISLAÇÃO PRÉ-CF/88.

\begin{tabular}{|c|c|c|c|}
\hline & EM DECISÃO FINAL & $\begin{array}{l}\text { OS MINISTROS DO STF SUSTENTARAM QUE A } \\
\text { QUESTÃO CENTRAL NO CASO DA ADIN } 4 \text { ERA O } \\
\text { ATO NORMATIVO DO BCB, QUE VINCULOU AS } \\
\text { INSTITUIÇÕES FINANCEIRAS E DETERMINOU A } \\
\text { OBSERVÂNCIA DA LEGISLAÇÃO PRÉ-CF/88 } \\
\text { SOBRE O SISTEMA FINANCEIRO NACIONAL, } \\
\text { DESOBRIGANDO-AS À OBEDIÊNCIA DO LIMITE } \\
\text { DE JUROS REAIS EM 12\% AO ANO. } \\
\text { EM DECISÃO FINAL, O STF SUSTENTOU A } \\
\text { AFIRMACCÃO DE QUE NĀO HÁ UM CONCEITO } \\
\text { PACÍFICO, EM DIREITO E ECONOMIA, SOBRE } \\
\text { JUROS REAIS, DEIXANDO A REGULAMENTAÇÃO } \\
\text { DO TEMA À FUTURA LEI COMPLEMENTAR } \\
\text { PREVISTA PELO ARTIGO 192. ENQUANTO ISSO, } \\
\text { CONTINUARIA VIGENTE A CIRCULAR DO BCB. }\end{array}$ & NÃO, POR MAIORIA $(6 \times 4)$ \\
\hline $\begin{array}{l}\text { 2. SOCIEDADES } \\
\text { CORRETORAS }\end{array}$ & $\begin{array}{l}\text { EM MEDIDA } \\
\text { CAUTELAR }\end{array}$ & NÃO HOUVE DECISÃO EM MEDIDA CAUTELAR. & - \\
\hline & EM DECISÃO FINAL & $\begin{array}{l}\text { O STF NÃO ANALISOU A QUESTÃO SE O CMN, } \\
\text { POR MEIO DE RESOLUÇÃO, PODERIA REEDITAR } \\
\text { TEXTO REJEITADO PELO LEGISLATIVO DE MEDIDA } \\
\text { PROVISÓRIA. O TRIBUNAL CONSIDEROU QUE } \\
\text { RESOLUÇÕES NÃO SÃO ATOS NORMATIVOS, COMO } \\
\text { MEDIDAS PROVISÓRIAS. A DISCUSSÃO ESTARIA } \\
\text { NO PLANO DA LEGALIDADE E NÃO DA CONSTITU- } \\
\text { CIONALIDADE DO DISPOSITIVO. }\end{array}$ & NÃO, POR UNANIMIDADE \\
\hline \multirow[t]{2}{*}{ 4. UDR } & $\begin{array}{l}\text { EM MEDIDA } \\
\text { CAUTELAR }\end{array}$ & $\begin{array}{l}\text { O STF NĀO RESPONDEU À QUESTÃO SE O BCB } \\
\text { PODERIA TER COMPETÊNCIA NORMATIVA, ATRI- } \\
\text { BUIIDA POR LEI ORDINÁRIA, PARA DISCIPLINAR } \\
\text { OPERAÇÕES DE CRÉDITO. SEGUNDO A CORTE, } \\
\text { O AUTOR DA ADIN NÃO ATACOU QUALQUER ATO } \\
\text { ESPECÍFICO DO BCB, QUE TIVESSE SIDO } \\
\text { PRATICADO NO ÂMBITO DA PREVISÃO LEGAL } \\
\text { DA COMPETÊNCIA NORMATIVA PARA DISCIPLINAR } \\
\text { OPERAÇÕES NO MERCADO FINANCEIRO. DESSA } \\
\text { FORMA, O TRIBUNAL AFASTOU ATÉ MESMO A } \\
\text { ANÁLISE DE CONSTITUCIONALIDADE DA PREVISÃO } \\
\text { LEGAL DESSA COMPETÊNCIA. }\end{array}$ & NÃO, POR UNANIMIDADE \\
\hline & EM DECISÃO FINAL & $\begin{array}{l}\text { POR DECISÃO MONOCRÁTICA, O STF DECIDIU QUE } \\
\text { A UNIÃO DEMOCRÁTICA RURALISTA (UDR) NĀO } \\
\text { TERIA LEGITIMIDADE ATIVA PARA A PROPOSICCÃO } \\
\text { DA ACCÃO DIRETA DE INCONSTITUCIONALIDADE, } \\
\text { POR SER UMA ENTIDADE HÍBRIDA. }\end{array}$ & - \\
\hline $\begin{array}{l}\text { 6. COOPERATIVA } \\
\text { DE CRÉDITO }\end{array}$ & $\begin{array}{l}\text { EM MEDIDA } \\
\text { CAUTELAR }\end{array}$ & $\begin{array}{l}\text { SEGUNDO O STF, PODERIA LEI ESTADUAL COMPLE- } \\
\text { MENTAR LEGISLAÇÃO FEDERAL, DESDE QUE A } \\
\text { AUTORIZAÇÃO PARA CRIACCÃO E O FUNCIONAMENTO } \\
\text { DE COOPERATIVA DE CRÉDITO CUMPRISSE REQUI- } \\
\text { SITOS DEFINIDOS EM LEGISLAÇÃO FEDERAL E } \\
\text { NORMAS EXPEDIDAS PELO CMN E BCB. }\end{array}$ & NÃO, POR UNANIMIDADE \\
\hline
\end{tabular}


082 : O STF E A CONSTRUÇÃO INSTITUCIONAL DAS AUTORIDADES REGULADORAS DO SISTEMA FINANCEIRO

\begin{tabular}{|c|c|c|c|}
\hline & EM DECISÃO FINAL & $\begin{array}{l}\text { A AC̣ÃO AINDA NÃO FOI JULGADA. DESDE } \\
20.11 .2003, \text { ESTÁ CONCLUSA AO NOVO } \\
\text { RELATOR, MINISTRO CEZAR PELUSO. }\end{array}$ & - \\
\hline \multirow[t]{2}{*}{ 8. BRB } & $\begin{array}{l}\text { EM MEDIDA } \\
\text { CAUTELAR }\end{array}$ & $\begin{array}{l}\text { SEGUNDO O STF, HOUVE INVASÃO DE COMPE- } \\
\text { TÊNCIA DE LEGISLAÇĀO FEDERAL PARA } \\
\text { DISCIPLINA DE EMPRÉSTIMOS NO MERCADO } \\
\text { FINANCEIRO, E, ESPECIALMENTE, LEI COMPLE- } \\
\text { MENTAR QUE REGULARÁ A ORGANIZAÇĀO, O } \\
\text { FUNCIONAMENTO E AS ATRIBUIÇŌES DO BCB. } \\
\text { ASSIM, EMBORA SEJAM NORMAS REFERENTES } \\
\text { ESPECIFICAMENTE AO BANCO REGIONAL DE } \\
\text { BRASÍLIA (BRB), INVADEM COMPETÊNCIA LEGIS- } \\
\text { LATIVA PRIVATIVA DA UNIĀO PARA LEGISLAR } \\
\text { SOBRE POLÍTICA DE CRÉDITO (ARTIGO 22, VII, } \\
\text { CF/88) E, DE LEI COMPLEMENTAR, PREVISTA } \\
\text { PELO ARTIGO 192, CF/88. }\end{array}$ & SIM, POR UNANIMIDADE \\
\hline & EM DECISÃO FINAL & $\begin{array}{l}\text { A AÇÃO AINDA NÃO FOI JULGADA. EM 08.07.2003, } \\
\text { HOUVE SUBSTITUIÇÃO DO RELATOR. ATUALMENTE, } \\
\text { ELA ESTÁ COM O MINISTRO JOAQUIM BARBOSA. }\end{array}$ & - \\
\hline \multirow[t]{2}{*}{ 9. PROER } & $\begin{array}{l}\text { EM MEDIDA } \\
\text { CAUTELAR }\end{array}$ & $\begin{array}{l}\text { NÃO, SEGUNDO O STF, HÁ IMPOSSIBILIDADE DE } \\
\text { NORMATIZAÇÃO DE MATÉRIA AFETA À LEI COMPLE- } \\
\text { MENTAR POR MEDIDA PROVISÓRIA. CONTUDO, HÁ } \\
\text { DUAS CONSIDERAÇÕES A SEREM FEITAS NO CASO } \\
\text { DO PROER: (I) ELE NĀO FOI INSTITUÍDO PELA } \\
\text { MEDIDA PROVISÓRIA, MAS SIM PELO CMN, ATRAVÉS } \\
\text { DA RESOLUCCÃO 2208/1995; E, COMO A LEI 4595/64, } \\
\text { RECEPCIONADA PELO SISTEMA JURÍDICO COM } \\
\text { STATUS DE LEI COMPLEMENTAR, DEU COMPETÊN- } \\
\text { CIA AO CMN PARA REGULAR A CONSTITUIÇĀO E O } \\
\text { FUNCIONAMENTO DE INSTITUIÇÕES FINANCEIRAS } \\
\text { E ZELAR POR SUA LIQUIDEZ (ARTIGO } 4^{\circ}, \text { VI E VIII), } \\
\text { ELE TERIA PODERES PARA TANTO. }\end{array}$ & NÃO, POR MAIORIA (6 X 3) \\
\hline & EM DECISÃO FINAL & $\begin{array}{l}\text { A QUESTÃO FOI PREJUDICADA. HOUVE PERDA DO } \\
\text { OBJETO DA AÇÃO, UMA VEZ QUE O AUTOR DA ADIN } \\
\text { NÃO FEZ ADITAMENTO DE POSTERIORES REEDI- } \\
\text { ÇÕES DA MEDIDA PROVISÓRIA. }\end{array}$ & - \\
\hline \multirow[t]{2}{*}{ 10. FGC } & $\begin{array}{l}\text { EM MEDIDA } \\
\text { CAUTELAR }\end{array}$ & $\begin{array}{l}\text { O CMN TERIA INVADIDO MATÉRIA RESERVADA AO } \\
\text { CONGRESSO NACIONAL. HAVERIA FLAGRANTE } \\
\text { INCONSTITUCIONALIDADE, SEGUNDO O STF, NA } \\
\text { CRIAÇĀO DO FUNDO GARANTIDOR DE CRÉDITO } \\
\text { (FGC) POR RESOLUÇÃO DO CMN, MATÉRIA } \\
\text { RESERVADA À LEI COMPLEMENTAR. NO ENTANTO, } \\
\text { O STF DECIDIU NÃO SUSPENDER SUA EFICÁCIA, } \\
\text { DEVIDO À POSSÍVEL REPERCUSSÃO NO AMBIENTE } \\
\text { ECONÔMICO-FINANCEIRO E PORQUE ELAS VISAM } \\
\text { À PROTECCÃO DO PEQUENO POUPADOR }{ }^{1} \text {. O } \\
\text { TRIBUNAL APENAS RETIROU DA COMPOSIÇĀO } \\
\text { DO PATRIMÔNIO DO FGC OS RECURSOS DO FUNDO } \\
\text { DE GARANTIA DE DEPÓSITOS E LETRAS IMOBILIÁ- } \\
\text { RIAS (FGDLI) E DA RESERVA PARA PROMOÇÃO DA } \\
\text { ESTABILIDADE DA MOEDA E DO USO DO CHEQUE } \\
\text { (RECHEQUE), QUE SERIAM DE DIFÍCIL RECUPERAÇÃO. }\end{array}$ & $\begin{array}{l}\text { SIM, PARCIALMENTE, } \\
\text { POR UNANIMIDADE }\end{array}$ \\
\hline & EM DECISÃO FINAL & $\begin{array}{l}\text { APÓS } 7 \text { ANOS DA DECISĀO EM MEDIDA CAUTELAR, } \\
\text { O STF JULGOU PELA PERDA DO OBJETO DEVIDO }\end{array}$ & -2 \\
\hline
\end{tabular}


AO ADVENTO DA EMENDA CONSTITUCIONAL 40/2003, QUE ALTEROU O ARTIGO 192 DA CF/88.

\begin{tabular}{|c|c|c|c|}
\hline 11. DEPÓSITO & EM MEDIDA & O STF NÃO DEFINIU UM ENTENDIMENTO DA & NÃO, POR MAIORIA $(8 \times 1)$ \\
\hline \multirow[t]{2}{*}{ BANCÁRIO } & CAUTELAR & 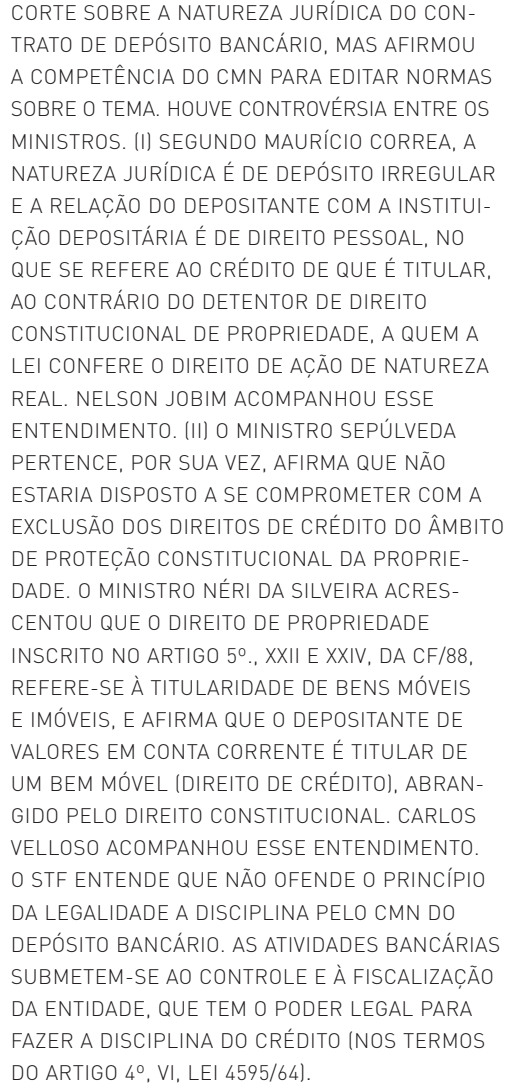 & \\
\hline & EM DECISÃO FINAL & $\begin{array}{l}\text { POSTERIORMENTE, A AÇĀO FOI JULGADA } \\
\text { PREJUDICADA PORQUE O AUTOR DA ADIN } \\
\text { NÃO APRESENTOU UMA PROCURAÇĀO COM } \\
\text { PODERES ESPECÍFICOS. }\end{array}$ & - \\
\hline $\begin{array}{l}\text { 12. AUDITORES } \\
\text { INDEPENDENTES }\end{array}$ & $\begin{array}{l}\text { EM MEDIDA } \\
\text { CAUTELAR }\end{array}$ & $\begin{array}{l}\text { O STF, DESDE PRONTO, RECONHECEU A } \\
\text { COMPETÊNCIA DO CMN E BCB PARA DISCIPLINAR } \\
\text { A ATIVIDADE DE AUDITORES INDEPENDENTES } \\
\text { EM INSTITUIÇŌES FINANCEIRAS. O ATO NORMA- } \\
\text { TIVO DISCIPLINA UMA DAS FORMAS DE CONTROLE } \\
\text { EXERCIDA PELO BCB, DENTRO DE SUAS COMPE- } \\
\text { TÊNCIAS LEGAIS, SOBRE AS INSTITUIÇŌES } \\
\text { FINANCEIRAS. O TRIBUNAL AFASTOU ALEGAC̄ÃO } \\
\text { DE QUE SE TRATAVA DE REGULAÇĀO DE EXERCÍ- } \\
\text { CIO DE ATIVIDADE OU PROFISSĀO E NĀO } \\
\text { DECLAROU INCONSTITUCIONAL A RESOLUÇĀO } \\
\text { DO CMN. }\end{array}$ & NÃO, POR UNANIMIDADE \\
\hline & EM DECISÃO FINAL & $\begin{array}{l}\text { EM DECISÃO FINAL, A AC̣̃̃O FOI JULGADA PREJUDI- } \\
\text { CADA POR REVOGAÇĀO DA RESOLUÇĀAO PELO CMN³. }\end{array}$ & - \\
\hline
\end{tabular}


$\mathbf{0 8 4}$ : O STF E A CONSTRUÇÃO INSTITUCIONAL DAS AUTORIDADES REGULADORAS DO SISTEMA FINANCEIRO

\begin{tabular}{|c|c|c|c|}
\hline 13. $\operatorname{CDC}$ & $\begin{array}{l}\text { EM MEDIDA } \\
\text { CAUTELAR }\end{array}$ & NÃO HOUVE DECISÃO EM MEDICA CAUTELAR. & - \\
\hline & EM DECISÃO FINAL & 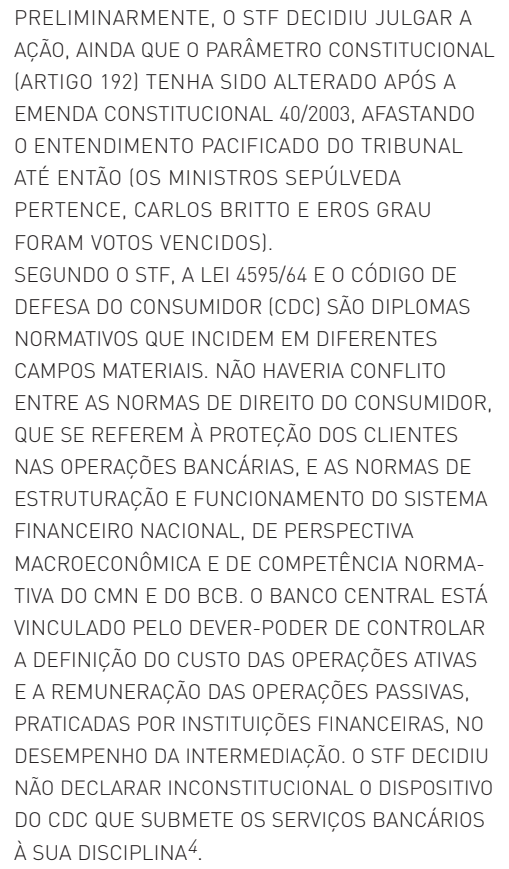 & NÃO, POR MAIORIA $(9 \times 2)$ \\
\hline & $\begin{array}{l}\text { EM EMBARGOS } \\
\text { DE DECLARAÇÃO }\end{array}$ & $\begin{array}{l}\text { O STF NÃO RESPONDEU DIRETAMENTE À } \\
\text { QUESTÃO DA APLICACCÃO DO CDC À FIXAÇÃO } \\
\text { DA TACA DE JUROS POR INSTITUICCÕES FINAN- } \\
\text { CEIRAS. NÃO HOUVE CONSENSO ENTRE OS } \\
\text { MINISTROS, SE SE TRATAVA DE MATÉRIA } \\
\text { RELACIONADA AO SISTEMA FINANCEIRO } \\
\text { NACIONAL, EM QUE TERIAM COMPETÊNCIA } \\
\text { PARA REGULACÃOO O CMN E O BCB, OU SE } \\
\text { SERIA APLICÁVEL O CDC. O TRIBUNAL } \\
\text { DECIDIU, POR UNANIMIDADE, APENAS } \\
\text { REFORMAR A EMENTA DA DECISÃO FINAL DA } \\
\text { ADIN, NOS PONTOS EM QUE HOUVESSE CON- } \\
\text { SENSO, ACATANDO O RECURSO PROPOSTO. }\end{array}$ & SIM, POR UNANIMIDADE \\
\hline
\end{tabular}

* Dados da pesquisa.

$1 \mathrm{O}$ ministro Marco Aurélio acrescentou que se "não fosse a repercussão do deferimento de uma liminar em maior extensão, considerados principalmente os pequenos investidores, os pequenos correntistas, não teria a menor dúvida em atuar no campo pedagógico, sinalizando ao autor do ato atacado (CMN) que ele também deve obediência à Lei Maior, à Constituição Federal” (ADIn MC 1398, p. 105).

2 Importante acrescentar que, após a decisão final do caso FGC, julgando pela perda do objeto, em termos práticos, ocorreu a ineficácia da medida cautelar que suspendeu da composição do patrimônio do FGC os referidos fundos. Assim, o CMN incorporou-os novamente à entidade (conforme notas explicativas do BCB às demonstrações financeiras, em 30 de junho de 2004). 3 Ressalte-se que, no entanto, não houve alteração substancial de conteúdo. O CMN apenas mudou de 4 para 5 anos o limite máximo para permanência de auditores independentes em instituições financeiras.

4 Um interessante voto, coerente econômica e juridicamente, é o voto do ministro Nelson Jobim. Apesar de ser um voto vencido, a discordância entre os ministros não era na fundamentação (ao menos, não no julgamento da decisão principal- isso somente será visível na análise dos votos dos embargos de declaração), mas sim na decisão - se seria julgada improcedente 
a ação direta de inconstitucionalidade ou se daria uma interpretação conforme a Constituição para excluir da incidência do $\mathrm{CDC}$ a taxa de juros.

De acordo com a Tabela 4, percebe-se que o STF articulou suas decisões em medida cautelar em sete dos dez casos analisados. Sendo que, em duas delas, ainda não houve julgamento final e, em cinco, a ação foi posteriormente julgada prejudicada; ou seja, a Corte decidiu não decidir, deixando aos poderes políticos a resolução final do conflito. Entretanto, o entendimento pacificado, no que se refere à perda do objeto da ação pela alteração de parâmetro constitucional, foi modificado. O STF decidiu julgar o caso CDC, ainda que tenha havido o advento da Emenda Constitucional 40/2003, que alterou o artigo 192. ${ }^{37}$

Ainda, o STF não respondeu às questões relativas à solução dos casos das Sociedades Corretoras, UDR, do Depósito Bancário e CDC. No entanto, é possível aferir que, sem responder diretamente às indagações, houve um posicionamento da Corte, qual seja, a manutenção da regulamentação pelo CMN e o reconhecimento implícito de sua competência normativa.

No caso das Sociedades Corretoras, o STF considerou que a resolução do CMN não era passível de controle de constitucionalidade por não ser ato normativo, mas meramente regulamentar. Posteriormente, irá prevalecer o posicionamento do caso ADIn 4, em que o STF considerou normativa uma circular do BCB. ${ }^{38}$

A questão central para este trabalho, portanto, é a manutenção da eficácia do ato normativo do CMN ou do BCB. No caso UDR, mesmo sendo a ADIn uma ação que permite uma ampla cognição pelo tribunal, ${ }^{39}$ a Corte decidiu não analisar a constitucionalidade da previsão legal (lei ordinária), que atribuía poderes ao BCB. Por sua vez, na análise do conceito jurídico de depósito bancário, apesar de não haver definição de um entendimento, o STF reconheceu a competência do CMN para a regulamentação da matéria. ${ }^{40}$

Por fim, no caso CDC, houve discussão que revelou profundas divergências no julgamento da decisão final da ADIn 2591. O ministro Eros Grau propunha que se aplicassem as normas de direito civil à disciplina da taxa de juros, e caberia ao Poder Judiciário a apreciação, caso a caso, de eventual abusividade, onerosidade excessiva ou outras distorções em sua composição contratual (ADIn ED 2591, p. 15). ${ }^{41}$ Contudo, há ministros, que acompanharam Carlos Britto, que se manifestaram a favor da aplicação do CDC à taxa de juros, no entanto, sem passar pela discussão do que seria matéria de lei complementar. ${ }^{42}$ Ao final, não se encontrando consenso entre os ministros, Sepúlveda Pertence, presidindo a sessão, altera substancialmente a ementa da ADIn 2591.

Assim, a discussão sobre a possibilidade da disciplina da taxa de juros, ou a atribuição de competência para tanto ser feita por lei complementar, é um dos temas subjacentes à discussão dos casos ADIn 4 e CDC. Em debates do Plenário, Sepúlveda Pertence pergunta ao ministro Eros Grau se estaria pronto, em seu voto, a procedência de uma ADIn que viesse a ser proposta contra lei ordinária que fixasse os custos das operações ativas e passivas das instituições financeiras (ADIn 2591, p. 196), ou seja, 
que regulamentasse atividades típicas do mercado financeiro. Ao que o ministro Eros Grau respondeu que sim, "se a Corte toda me acompanha" (ADIn 2591, p. 196). Nessa ADIn, a decisão foi tomada por maioria $(9 \times 2)$, com o voto do ministro Eros Grau sendo condutor. ${ }^{43} \mathrm{Na}$ verdade, esse fundamento é compartilhado pelos votos vencidos dos ministros Carlos Velloso e Nelson Jobim, em que houve dissidência somente em relação à decisão: se seria julgada improcedente a ação direta de inconstitucionalidade ou se daria uma interpretação conforme a Constituição, julgando parcialmente procedente, para excluir a aplicação do CDC à taxa de juros. A real divergência, de fato, apareceu somente na decisão dos embargos de declaração.

Nesse tema, cabe analisar também uma outra decisão do tribunal: a súmula 648, de 2003. ${ }^{44}$ Segundo ela, a norma da Constituição, revogada pela Emenda Constitucional $40 / 2003$, que limitava a taxa de juros reais em $12 \%$ ao ano, tinha sua aplicabilidade condicionada à edição de lei complementar. $O$ intuito era pacificar o entendimento consolidado na ADIn n. 4, em todas as instâncias do Poder Judiciário, ${ }^{45}$ mas também revela que a disciplina das taxas de juros cabe à lei complementar, que vier disciplinar o sistema financeiro. De acordo com o ministro Eros Grau, voto condutor no julgamento do caso CDC, "tudo que exceda a taxa base de juros, os percentuais que a ela são adicionados e findam por compor o spread bancário, tudo isso pode e deve ser controlado pelo Banco Central e, se o caso, pelo Poder Judiciário” (ADIn 2591, p. 189). ${ }^{46}$

Ainda em relação ao caso ADIn 4, há uma observação a ser feita sobre a interpretação corrente dada à essa decisão, de que seria necessária uma única lei complementar, que disciplinasse todo o sistema financeiro. ${ }^{47}$ Primeiramente, a frase "só o tratamento global do Sistema Financeiro Nacional, na futura lei complementar, com a observância de todas as normas do caput, dos incisos e parágrafos do artigo 192, é que permitirá a incidência da referida norma sobre juros reais e desde que estes também sejam conceituados em tal diploma”, é encontrada somente na ementa do acórdão que tem mais de 130 páginas. ${ }^{48}$ Apropriado ou não, foi esse o sentido majoritário atribuído à decisão do STF na época. Assim, em 2003, o Congresso Nacional alterou o artigo 192 da Constituição para modificar a redação do dispositivo, alterando "lei complementar" por "leis complementares". ${ }^{49}$ Essa alteração mostra que, mais uma vez, funcionou o sistema de checks and balances brasileiro. O Legislativo alterou, primeiramente, a redação constitucional para, posteriormente, pensar a regulamentação do sistema financeiro nacional, em respeito ao que se interpretou, na época, sobre a decisão da Corte.

Outra ponderação relevante, a partir da análise desses casos, é a constatação de que o STF está sujeito à argumentação político-econômica. No caso ADIn 4, isso fica especialmente claro. ${ }^{50} \mathrm{O}$ ministro relator Sydney Sanches trouxe, no corpo de seu voto, um estudo do Banco Central, incorporado pelo contestado parecer da Consultoria Geral da República, que previa a calamidade do sistema financeiro nacional se houvesse o tabelamento de juros e, posteriormente, utilizou-o como o próprio fundamento de sua decisão. ${ }^{51}$ 
Essa suscetibilidade aos argumentos econômicos também aparece no julgamento do caso FGC. Os ministros declaram a evidente inconstitucionalidade da disciplina por resolução do $\mathrm{CMN}$, contudo, mantêm a regulamentação "sob pena de gerar tumulto, desordem e insegurança na comunidade dos correntistas e dos poupadores" (ADIn MC 1398, p. 99). ${ }^{52}$

Ainda, observa-se que, nos casos da Cooperativa de Crédito, BRB, Proer, Depósito Bancário e Auditores Independentes II, houve expresso reconhecimento pela Corte da competência normativa do $\mathrm{CMN}$ e $\mathrm{BCB}$ para disciplinar: cooperativas de crédito, contrato de depósito bancário, empréstimos bancários, depósito compulsório, constituição e funcionamento de instituições financeiras e o zelo por sua liquidez e, por fim, atividade de auditores independentes em instituições financeiras. Em relação ao caso Proer, o STF reconheceu até mesmo que uma resolução do CMN poderia o que nem mesmo uma medida provisória pôde. ${ }^{53} \mathrm{E}$, no caso $\mathrm{CDC}$, em sua primeira decisão, o tribunal reconhecia a competência dos órgãos do Poder Executivo para a fixação da taxa básica de juros. ${ }^{54}$

Por fim, um último comentário, refere-se à convergência dos ministros em seus votos. Somente em 4, de 12 decisões tomadas pelo Pleno nesse tema, houve dissidências e a decisão final foi tomada por maioria. Dessa forma, pode-se concluir que os ministros do tribunal tendem a deliberar no mesmo sentido no que se refere à competência normativa para regular o Sistema Financeiro Nacional.

\section{Conclusão}

Pela análise dos casos, observa-se que um comportamento reiterado do STF era deixar aos poderes políticos a disciplina do sistema financeiro nacional. Afinal, dentre os 14 casos, sete foram julgados prejudicados (sem uma decisão final), e dois ainda não foram julgados. O tribunal posicionava-se, sobretudo, por meio de decisões em medida cautelar, em relação a diversos temas do sistema financeiro. Além disso, somente houve suspensão dos efeitos de ato normativo questionado, no que se refere especificamente aos atos das autoridades reguladoras, somente no caso dos Servidores do BCB II, de portaria que disciplinava o plano de carreira para seu quadro pessoal.

Entretanto, essa atuação "passiva" da Corte modificou-se em 2006, no julgamento do caso CDC. Essa alteração de posicionamento já se entrevia no caso do presidente do $\mathrm{BCB}$ e no chamamento pela Corte do controle de um agente político importante para o cenário econômico-institucional brasileiro.

Em relação ao sistema financeiro e a partir dos casos selecionados, têm-se as seguintes conclusões, que servem de parâmetro para a edição das futuras leis que visem regular o Sistema Financeiro Nacional:

1. É de competência normativa do $\mathrm{CMN}$ e do $\mathrm{BCB}$, dentro da previsão legal, ${ }^{55}$ a regulamentação de cooperativas de crédito, contrato de depósito bancário, 
empréstimos bancários, depósito compulsório, constituição e funcionamento de instituições financeiras e o zelo por sua liquidez, atividade de auditores independentes em instituições financeiras e, por fim, a definição da taxa básica de juros.

2. É de competência da lei complementar, prevista pelo artigo 192, definir as regras gerais do Fundo Garantidor de Crédito e a disciplina da taxa de juros.

3. Cabe ao Poder Judiciário apreciar, caso a caso, eventual abusividade, onerosidade excessiva ou outras distorções na composição contratual da taxa de juros.

4. Pode lei ordinária disciplinar regime jurídico de servidores do BCB.

Retoma-se a sugestão de que a reestruturação do BCB, para eventual concessão de autonomia ao seu presidente e diretores, seja feita por lei complementar com pedido de urgência, se o momento político o exigir. Há risco de que, se feita de outra forma, por lei ordinária ou medida provisória, ela seja declarada inconstitucional pelo STF. Em relação ao quadro de servidores do $\mathrm{BCB}$, no entanto, não parece haver problemas em ser feita sua eventual alteração por lei ordinária. Além disso, há certa liberdade para a composição da lei complementar. Além da alteração da Emenda Constitucional 40/2003, que, em tese, permitiu a regulamentação fatiada do artigo, o ministro Eros Grau deu a orientação de que o artigo 192 é somente norma-objetivo, após essa modificação. Não existiria mais um elenco determinando o conteúdo do que deve ser disciplinado, como previsto anteriormente. Poder-se-ia interpretar essa orientação como liberdade para o Congresso Nacional determinar esse conteúdo.

No entanto, a partir da análise dos casos, ainda há uma indagação: afinal, quem define a pauta do STF, no que se refere ao sistema financeiro nacional? Não há como inferir quais são os temas que entram, e quando, no julgamento do órgão. Para responder a essa pergunta, seria interessante verificar também quais as ADIns, que se referem ao poder normativo das autoridades reguladoras, que ainda aguardam a resposta do STF.

Cite-se, como exemplo, a ADIn 1495, proposta pelo PDT, contra dispositivos da Resolução 2303 do CMN, que proíbe a cobrança de tarifas para certos serviços bancários. Essa ADIn foi distribuída aos ministros em 1996 e ainda não foi julgada. Uma pesquisa como esta vai além dos limites deste artigo, que visa analisar essencialmente a argumentação do STF nos casos julgados, para saber qual é seu posicionamento. Contudo, essa é uma discussão relevante para uma próxima investigação. ${ }^{56}$

Por fim, é evidente que este artigo é apenas parte de um trabalho muito maior para a construção das autoridades reguladoras. No entanto, é ponto essencial, para repensar o papel dessas instituições político-econômicas, a avaliação da atuação da Corte Constitucional brasileira nesse processo no exercício de interpretação da Constituição Federal.

: ARTIGO APROVADO (12/01/2009) : RECEBIDO EM 30/07/2008 


\section{NOTAS}

1 Luiz Sérgio Guimarães, "Analistas temem que PAC possa constranger a autonomia do BC", Valor Econômico, 19/01/2007; James Allen, “O debate sobre autonomia é oficial”, O Estado de S.Paulo, 17/02/2005; Camila Duran Ferreira, "O limite entre autonomia e responsabilidade", Valor Econômico, 14/07/2005; Gustavo Loyola, "Banco Central: 40 anos é uma boa idade para a maioridade”, Valor Econômico, 10/01/2005.

2 Para o conteúdo da discussão sobre a autonomia do Banco Central do Brasil, no âmbito da Câmara dos Deputados, ver documento elaborado por Pereira (2003), como consultor legislativo da Área VII, Sistema Financeiro, Direito Comercial, Direito Econômico e Defesa do Consumidor. Além disso, após a promulgação da Lei de Responsabilidade Fiscal (Lei complementar 101/2000), o Congresso Nacional tornou-se um dos atores políticos responsáveis pela prestação de contas do $\mathrm{BCB}\left(\operatorname{artigo} 9^{\circ}, \S 5^{\circ}\right.$ ), assim como, no decorrer dos anos após a promulgação da Constituição Federal, viu-se a instalação de várias Comissões Parlamentares de Inquérito (CPIs), sendo uma delas muito relevante para investigação das atividades exercidas pelas autoridades reguladoras do mercado financeiro, a conhecida CPI dos Bancos. Ainda, no domínio da regulação do mercado de câmbio brasileiro, tem-se assistido nos últimos anos a constantes mudanças no arcabouço normativo. Em especial, é importante fazer referência à Lei 11371, de 2006, que introduziu mudanças significativas em um sistema que perdurava desde o governo Getúlio Vargas - diga-se, de passagem, que se trata de lei ordinária, ainda que regulamente matéria relacionada ao Sistema Financeiro Nacional.

3 Para um estudo sobre o uso das ações diretas de inconstitucionalidade por partidos políticos de oposição ao governo para impedir ou alterar a implementação de políticas públicas, ver Taylor (2005).

4 Os estudos sobre esse tema não são recentes e procuram demonstrar o papel do Judiciário como ator na formulação de políticas públicas e na construção de importantes conceitos jurídicos para o desenvolvimento de políticas econômicas. Já em 1957, em uma interessante pesquisa empírica, Robert Dahl aponta casos em que a Suprema Corte norte-americana atua como "policy-maker" nacional (Dahl, 2001; reprinted). E, anteriormente, foi publicada a obra de Nussbaum (1950) que, a partir da análise das decisões dessa Corte, procurou definir o papel desse tribunal na construção do conceito de moeda, entre outros, relacionados ao sistema financeiro.

5 Judicial review é poder pelo qual os juízes controlam atos do Poder Legislativo ou Executivo, a partir da aferição de sua constitucionalidade. No sistema norte-americano, esse sistema foi inaugurado pela Suprema Corte no julgamento do caso Marbury.

6 O sistema brasileiro adota o princípio da proibição do "non liquet", segundo o qual o juiz está obrigado a decidir a causa levada à sua apreciação.

7 A Constituição Federal de 1988 introduziu duas novidades: a ação direta de inconstitucionalidade por omissão (artigo 103, $\S 2^{\circ}$ ) e a ampliação da legitimação para a propositura da ação direta de inconstitucionalidade (artigo 103), antes restrita ao Procurador-Geral da República. Além disso, novos instrumentos foram introduzidos no sistema jurídico durante a década de 1990, como as ações de descumprimento de preceito fundamental, que ampliaram os mecanismos jurídicos para o controle de constitucionalidade e também se permitiu a participação de amicus curiae no processo constitucional (Lei 9868/1999).

8 É importante mencionar, no entanto, que não foram encontradas ações declaratórias de constitucionalidade (ADCs) que estivessem dentro do âmbito material da pesquisa proposta por este artigo sobre as autoridades reguladoras CMN e BCB.

9 O sistema de controle de constitucionalidade brasileiro tem dois critérios: o controle difuso e o controle abstrato ou concentrado. O primeiro é aquele exercido, tanto pelos tribunais como pelos juízes, na análise de um caso concreto, em que pode ser declarada incidentalmente a inconstitucionalidade de uma norma jurídica. O controle abstrato, por sua vez, somente pode ser exercido por uma corte especial, a partir da análise do próprio diploma normativo. Para interessante estudo sobre o sistema brasileiro de controle de constitucionalidade, ver Clève (2000).

10 Para que uma decisão do Supremo Tribunal Federal, em recurso extraordinário (controle de constitucionalidade difuso), tenha seus efeitos estendidos a todos, indistintamente da figuração processual, o Senado Federal deve suspender definitivamente a eficácia da norma jurídica, após a deliberação da Corte (artigo 52, X, CF/88). 
11 Conforme Emenda Constitucional 45/2004, que introduziu o artigo 102, $\S 3^{\circ}$, à Constituição Federal, e parágrafo único do artigo 28 da Lei $9868 / 1999$.

12 Por esse motivo, decisões do STF sobre aspectos puramente monetários dos planos heterodoxos de estabilização econômica (Plano Cruzado, Plano Bresser, Plano Verão, Plano Collor I e Plano Collor II) e do Plano Real - como, por exemplo, a definição de índices de correção monetária, o congelamento de preços e ativos financeiros, os critérios de conversão para nova moeda, entre outros -, foram excluídos da análise. No entanto, em relação especificamente ao Plano Real, será analisada a decisão do STF sobre a alteração da composição do CMN, por ser um aspecto institucional relevante.

13 Assim, analisaram-se decisões judiciais que se referiam ao desempenho das entidades na regulação de condutas, que têm como fim a proteção dos hipossuficientes em sua relação com as instituições financeiras ou a repressão às condutas anticoncorrenciais, e na regulação prudencial e sistêmica, relativa à supervisão e controle de instituições financeiras, consideradas isoladamente, e do sistema financeiro como um todo, funções exercidas também pelo Banco Central e Conselho Monetário Nacional.

14 Nesse mesmo sentido, uma interessante pesquisa, que também apresenta os resultados de forma qualitativa, é Veiga da Rocha (2004). Há, no entanto, pesquisas sobre o conteúdo de decisões judiciais, que apresentam os resultados a partir de uma perspectiva quantitativa. É o caso dos trabalhos de Castro (1997), Duran Ferreira e outros (2005) e Análise Justiça (2006). Em outro sentido, há também estudos sobre o Poder Judiciário, a partir de entrevistas com juízes e sua visão sobre o julgamento de determinados temas, como Sadek (1995), Vianna e outros (1997), Pinheiro (2003) e Ferrão (2006). Uma entidade que se destaca também pela produção anual dessa modalidade de pesquisa é a Escola de Formação da Sociedade Brasileira de Direito Público (SBDP), em São Paulo.

15 O Plenário do STF é composto por 11 ministros, dentre eles um presidente. É da competência desse órgão máximo o julgamento das ADIns. Na sessão para julgar a constitucionalidade de ato normativo, devem estar presentes, no mínimo, 8 ministros (artigo 22, Lei 9868/1999). E, para que seja declarada a inconstitucionalidade do dispositivo jurídico, a decisão deve ser partilhada por, no mínimo, 6 ministros (artigo 23, Lei 9868/1999). Além disso, foram encontradas decisões monocráticas, que são tomadas individualmente por um ministro relator do caso, sem passagem pelo Plenário. Normalmente, elas se inserem no chamado "saneamento do processo", em que o relator encontrou alguma razão jurídica processual para julgar a ação prejudicada e por fim ao processo.

16 A esse campo foi acrescentado "Redator para acórdão", no caso de o relator original ter seu voto vencido ou ter saído do tribunal antes do julgamento final da ação.

17 As decisões judiciais foram encontradas a partir do site oficial do Supremo Tribunal Federal <http://www.stf.gov.br>, em "Pesquisa de Jurisprudência”, "Processos: Consulta", "A Constituição e o STF” e "Índice de ADIns e ADCs”. Além disso, foi consultado também o índice da Revista Trimestral de Jurisprudência, revista oficial da entidade.

18 As ADIns 3289 e 3290 foram consideradas como uma mesma ação por este artigo, uma vez que contestavam o mesmo ato normativo e foram decididas conjuntamente pelo STF. A única diferença refere-se à parte autora. A primeira foi interposta pelo antigo Partido da Frente Liberal (PFL) e, a segunda, pelo Partido da Social Democracia Brasileira (PSDB).

19 A medica cautelar antecipa os efeitos de uma decisão final, de forma preventiva. Ela pode ser deferida se presente dois requisitos: razoável probabilidade do direito alegado e o perigo da demora do julgamento final da ação (periculum in mora).

20 O Partido dos Trabalhadores (PT) foi responsável pela metade deste número (3), seguido pelo Partido Democrático Trabalhista (PDT), com 2 ADIns, e pelo Partido da Frente Liberal (PFL) e Partido da Social Democracia Brasileira (PSBD), que iniciaram as ADIns 3289 e 3290 , sobre o mesmo objeto.

21 As entidades são a Confederação Nacional de Profissionais Liberais (CNPL), a Confederação Nacional do Sistema Financeiro (Consif), e a União Democrática Ruralista (UDR), que, posteriormente, perdeu sua legitimidade processual por ser considerada entidade híbrida, segundo entendimento do STF.

22 Governadores de São Paulo e Distrito Federal interpuseram ação direta de inconstitucionalidade contra lei estadual que tratava de matéria relativa ao sistema financeiro. 
23 Desconsiderou-se na Tabela 2 a ADIn ED 2591 (embargo de declaração), por se tratar de uma demanda dirigida ao STF para corrigir contradição em decisão principal.

\section{Artigo $128, \S 1^{\circ}, \mathrm{CF} / 88$}

25 Como se verá adiante, a referida contestação foi a criação do Fundo Garantidor de Crédito (FGC). O STF somente declarou a inconstitucionalidade, em medica cautelar, da incorporação de dois fundos ao patrimônio da entidade, mantendo sua instituição por resolução do CMN. Essa decisão durou somente 7 anos, porque o STF julgou a ação prejudicada posteriormente, e o CMN incorporou-os ao FGC (conforme notas explicativas do BCB às demonstrações financeiras, em 30.06.2004).

26 O parâmetro constitucional no âmbito desta pesquisa é o artigo 192, da Constituição Federal, alterado pela Emenda Constitucional 40/2003.

27 Acredita-se que essa argumentação do STF, apesar de não estar expressamente declarado, seja devido ao CMN fazer parte da Administração Pública direta.

28 Segundo o relator Moreira Alves, ela não teria a intensidade porque não deixaria de ser relevante também o argumento da Presidência da República, de que a objeção se coloca no sentido de que o CMN não estaria compreendido em "instituições financeiras públicas", conforme o inciso IV do artigo 192 (redação anterior à EC 40: a lei complementar irá dispor sobre "IV - a organização, o funcionamento e as atribuições do banco central e demais instituições financeiras públicas e privadas”).

29 Conforme declaração do ministro relator Gilmar Mendes: "Ora, estamos falando do presidente do Banco Central! Todos sabemos o papel e a importância dessa autoridade na vida nacional” (ADIn 3289/3290, p. 15).

30 Segundo o ministro relator das ADIns 3289 e 3290, "de fato, as decisões tecnocráticas ou políticas podem e devem ser contestadas. A sua juridicidade deve ser auferida. É a própria constituição que cria mecanismos para aferição da legitimidade dos atos do Poder Público. Mas é o próprio sistema que exige, em relação a certos agentes, um tratamento diferenciado, no que toca à impugnação judicial de atos praticados no exercício da função, tendo em vista uma perspectiva de estabilidade que interessa às próprias instituições públicas” (p. 39). Interessante notar que o STF julgou diretamente a ação, mesmo tendo sido feito um pedido de julgamento de medida cautelar no caso do Presidente do BCB

31 Trata-se do sistema de "freios e contrapesos", adotado pela Constituição Federal, a partir da ideia de previsão de separação de poderes e de mecanismos de controle de uma instituição pela outra.

32 "E é justamente por isso que está consagrada, em nosso sistema constitucional, a instituição da prerrogativa de foro. Além de evitar o que poderia ser definido como uma tática de guerrilha - nada republicana, diga-se - perante os vários juízos de primeiro grau, a prerrogativa de foro serve para que os chefes das principais instituições públicas sejam julgados perante um órgão colegiado dotado de maior independência e inequívoca seriedade” (ADIn 3289, Gilmar Mendes, p. 21).

33 Importante ainda considerar que 6 é o número mínimo para a declaração de constitucionalidade ou inconstitucionalidade de um ato normativo submetido a controle (artigo 23, Lei 9868/1999).

34 Esse assunto é tão caro ao STF, que o ministro relator do caso do Presidente do BCB afastou as alegações de vício formal na edição da medida provisória, que deu status de Ministro de Estado ao Presidente do BCB, porque, segundo ele, "considerando que ainda estamos numa fase de consolidação do novo modelo trazido pela Emenda 32 para as medidas provisórias, não vejo como adotar interpretação com os rigores pretendidos pelo requerente na ADI 3289” (p. 24, 25). Essa Emenda prevê que o exame de medida provisória deve passar pela comissão mista de deputados e senadores, antes de serem apreciadas, em sessão separada, pelo plenário de cada uma das casas do Congresso Nacional, o que não ocorreu no caso concreto. Assim, essa argumentação pode demonstrar que o STF está chamando para seu controle o conteúdo da medida provisória.

35 Nesse caso, o projeto de lei, de iniciativa do Presidente da República, segue o rito definido pelo artigo 64, $\S \S$ $1^{\circ}$ e $2^{\circ}$, da CF/88. A Câmara dos Deputados e o Senado Federal têm até 45 dias, cada qual sucessivamente, para se manifestarem, ou sobrestar-se-ão todas as deliberações legislativas da respectiva Casa. 
092 : O STF E A CONSTRUÇÃO INSTITUCIONAL DAS AUTORIDADES REGULADORAS DO SISTEMA FINANCEIRO

36 Redação anterior à Emenda Constitucional 40/2003: “artigo 192, § 3. As taxas de juros reais, nelas incluídas comissões e quaisquer outras remunerações direta ou indiretamente referidas à concessão do crédito, não poderão ser superiores a doze por cento ao ano; a cobrança acima deste limite será conceituada como crime de usura, punido, em todas as suas modalidades, nos termos que a lei determinar".

37 Segundo o ministro Nelson Jobim, “o regime jurídico aplicado aos bancos e ao SFN é tema demasiadamente sensível do ponto de vista econômico, político e social para ficar restrito a uma previsão constitucional de tom mais analítico. Está a tratar de tema fundamental do ponto de vista institucional” (ADIn 2591, p. 74, 75). Nessa mudança de entendimento, ficaram vencidos os ministros Sepúlveda Pertence, Eros Grau e Carlos Britto.

38 "Lembro-me de que o Banco Central tem poderes regulatórios autônomos e que, portanto, podem vir a ser objeto de perquirição do Supremo Tribunal Federal para efeito de declaração de inconstitucionalidade” (ADIn 4, Célio Borja, p. 809).

39 O julgamento em uma ação direta de inconstitucionalidade é bastante especial. Por exemplo, não se admite desistência de uma proposta de ADIn (artigo 5º Lei 9868/1999). Além disso, o STF, na análise do caso, tem faculdade do amplo conhecimento e não está limitado aos fundamentos do autor (pedido mediato), mas somente ao pedido imediato.

40 É realmente lastimável que essa ação tenha sido julgada prejudicada, posteriormente à decisão da medida cautelar. Seria muito relevante a definição pelo STF do conceito jurídico de depósito bancário. Ao menos, em medida cautelar, o tribunal deu os parâmetros para o debate.

41 O ministro Marco Aurélio o acompanhou: "Vamos deixar essas questões para processos subjetivos" (ADIn ED 2591, p. 50).

42 O ministro Eros Grau discorda e afirma que, no caso da aplicação do CDC às taxas de juros, estariam excluídos dessa proteção as micro e pequenas empresas, porque não são destinatárias finais (“O que Vossa Excelência está propondo é que se exclua a proteção total em relação à pequena e média empresa, que merecem mais proteção. [...] $\mathrm{O}$ resultado do raciocínio de Vossa Excelência restringe, protege os bancos, protege as instituições financeiras. Sei que não é essa a intenção de Vossa Excelência”, ADIn ED 2591, p. 42).

43 Em decisão posterior, nos embargos de declaração, na ADIn ED 2591, o ministro Sepúlveda Pertence alerta que: "se amanhã vier uma lei ordinária e regular taxa de juros, será fascinante a discussão sobre se ela violar ou não, o que, apesar da ablação dos seus parágrafos, continua contido no caput do art. 192, porque integrante do sistema financeiro. Mas isso não é objeto desta ação direta” (ADIn ED 2591, p. 41).

44 Outra súmula relacionado ao sistema financeiro nacional é a 596, de 1976. Segundo ela, a disciplina legislativa sobre o crime de usura não se aplica às taxas de juros e a outros encargos cobrados em operações realizadas por instituições públicas ou privadas, que integram o sistema financeiro.

45 Isso ocorreu também devido à decisão expressa do ministro Sydney Sanches deixar aos processos subjetivos a discussão da aplicação imediata do tabelamento de juros, entre a decisão da medida cautelar e o julgamento final pelo tribunal.

46 A questão da abusividade dos juros foi tema recentemente submetido a procedimento especial no Superior Tribunal de Justiça, no julgamento do Recurso Especial n. 1.061.530/RS, relator Ari Pargendler. Todos processos que discutiam esse tema em contratos bancários, dentre outros, foram suspensos e diversos órgãos públicos e da sociedade civil foram oficiados para que manifestassem seu interesse no processo.

47 Para uma interessante crítica a essa interpretação, ver Silva e Veiga da Rocha (2002). Há dissidência sobre essa interpretação mesmo entre os ministros do tribunal. No julgamento da ADIn 2591, Nelson Jobim declara "várias vezes tenho ouvido, inclusive está no relatório, que o tribunal teria decidido que essa lei complementar do sistema financeiro teria de ser uma lei única (...) Repete-se isso como se fosse algo assente” (p. 58).

48 O que mostra a validade de uma coerente observação feita pelo ministro Nelson Jobim (ADIn ED 2591, p. 51), ao constatar a dispersão de fundamentos do Plenário no julgamento do caso CDC, declara que "num caso como este, a ementa será mais citada do que o acórdão e os votos que o compuseram". 
49 A alteração foi feita pela Emenda Constitucional 40/2003.

50 Mesmo nos votos vencidos há a utilização de argumentos econômicos, mas no sentido do autor da ADIn. O ministro Carlos Velloso fala da "importância do elemento político-sociológico na interpretação" e acrescenta: "Nós sabemos, Senhor Presidente, que as taxas de juros que estão sendo praticadas, hoje, Brasil, são taxas que nenhum empresário é capaz de suportar. Nós sabemos que o fenômeno que se denomina, pitorescamente, de 'ciranda financeira', é que é a tônica, hoje, do mercado financeiro, engordando os lucros dos que emprestam dinheiro e empobrecendo a força de trabalho e do capital produtivo. Tudo isso eu devo considerar e considero, Senhor Presidente, quando sou chamado, como juiz da Corte Constitucional, a dizer o que é a Constituição" (p. 820). Ainda, Paulo Brossard: "O eminente relator em seu voto deu notícia de um documento oficial, não sei se do Banco Central, se do Secretário Especial de Política Econômica, segundo o qual seria uma catástrofe nacional a adoção da taxa de até $12 \%$, como prescreve a Constituição. Dante não teve expressões tão horripilantes para pintar o inferno, em um dos círculos, aliás, o florentino reservou lugar para os usurários... Fica-se a saber que seria uma desgraça se o País, cumprindo a sua Constituição, passasse a conviver com o juro tradicional, com o qual o Brasil cresceu e desenvolveu-se” (p. 834). Em outro sentido, em voto que acompanhou o relator, o ministro Célio Borja, apesar de sua argumentação ter sido contra a apreciação de razões econômicas, ele deixa transparecer que houve apreciação desses argumentos e, que, por esse motivo, é importante que se deixe a disciplina para os poderes políticos. Assim, ao falar sobre a sustentação oral do autor da ADIn, diz que esta "fixou-se na qualidade da norma, na sua utilidade para a vida os brasileiros, para a economia nacional, para atividade produtiva, mas, como magistrados, não podemos entrar nessa apreciação. A questão da determinação da auto-aplicabilidade das normas constitucionais, além de ser um problema técnico e algumas vezes árduo, é uma grave questão política, porque ao dizer se uma norma depende ou não de complementação legislativa o Supremo Tribunal Federal poderá estar na iminência de usurpar competência própria de outro poder. (...) Os argumentos ad terrorem, a mim, pessoalmente, não impressionam e acredito nem ao tribunal. Se o País vier, em algum momento, a adotar juros nominais ou reais de doze por cento, a sua economia estará gravemente comprometida. Não entramos nesse tipo de apreciação, simplesmente, estamos distantes dessas considerações que são, certamente, o ofício dos poderes políticos da Nação, não dos juízes, dos magistrados” (p. 846).

51 "Acolho, no substancial, a fundamentação dos pareceres da Consultoria-Geral da República (SR-70/88), aqui impugnado, da Advocacia Geral da União (...) e dos juristas e professores Hely Lopes Meirellles, Caio Tácito, José Frederico Marques, Manoel Gonçalves Ferreira Filho, Celso Bastos, Ives Gandra da Silva Martins, José Alfredo de Oliveira Baracho, Rosah Russomano, Cid Heráclito de Queiroz, Arnold Wald e Geraldo Vidigal” (ADIn 4, p. 805).

52 A inconstitucionalidade do FGC já havia sido pronunciada no voto do ministro Ilmar Galvão, no caso Proer. Segundo ele, sem o exame da resolução do CMN, que criou o Proer, não havia como se "verificar se o interesse dos credores, no caso, restou protegido por meio de fundo ou seguro organizado com o concurso de recursos da União, o que seria vedado pelo inc. VI do referido artigo 192 da CF” (ADIn 1376, p. 480).

53 O posicionamento do tribunal foi o de que o Proer não havia sido instituído pela medida provisória, mas sim pelo CMN como preceitua expressamente o artigo $1^{\circ}$ da medida ("O Programa de Estímulo à Reestruturação e ao Fortalecimento do Sistema Financeiro Nacional, instituído pelo Conselho Monetário Nacional...”), por meio da Resolução 2208, de 6.11.1995. No entanto, a Medida Provisória 1179 é de 3.11.1995, anterior à referida resolução.

54 Segundo o ministro Eros Grau, “a fixação dessa taxa não pode ser operada senão desde a perspectiva macroeconômica" (ADIn 2591, p. 183).

55 Lei 4595/64, recebida pela Constituição Federal de 1988 com status de lei complementar.

56 Ela envolveria também uma análise do verdadeiro poder legislativo exercido pelo STF na disciplina do processo constitucional, através de seu regimento interno. 
094 : O STF E A CONSTRUÇÃO INSTITUCIONAL DAS AUTORIDADES REGULADORAS DO SISTEMA FINANCEIRO

\section{REFERÊNCIAS BIBLIOGRÁFICAS}

ANÁLISE Justiça: Supremo e Superior Tribunal. Revista Análise, 2005. Disponível em:<http://www.analise.com>. CAPPELLETTI, Mauro. Juizes legisladores? Porto Alegre: Fabris, 1999.

CLÈVE, Clemerson. A fiscalização abstrata da constitucionalidade no direito brasileiro. $2^{\mathrm{a}}$ ed, São Paulo: Revista dos Tribunais, 2000.

DAHL, Robert. Decision-making in a democracy: the Supreme Court as a national policy-maker (1957), Emory Law Journal, Emory University School of Law, 2001 (reprinted).

DURAN FERREIRA, Camila et al. O judiciário e as políticas públicas de saúde no Brasil: o caso Aids. Prêmio Ipea 40 anos. Brasília: Ipea, 2005.

FARIA, José Eduardo Campos de Oliveira. Justiça e conflito - os juizes em face dos novos movimentos sociais. 2. ed. São Paulo: RT, 1992.

FERRÃO, Brisa Lopes; RIBEIRO, Ivan César. Os juízes brasileiros favorecem a parte mais fraca? Berkeley Program in Law \& Economics: ALACDE Annual Papers. Paper 26, May 15, 2006.

NUSSBAUM, Arthur. Money in the Law National and International. Brooklyn: The Foundation Press Inc., 1950. PEREIRA, Eliacir Marques. Autonomia do Banco Central: subsídios para discussão. Documento da Área VII, Câmara dos Deputados, Brasília, 2003.

PINHEIRO, Armando Castellar. Judiciário, reforma e economia: a visão dos magistrados. Texto para Discussão 966. Brasília: Ipea, 2003.

SADEK, Maria Tereza. Org. Uma introdução ao estudo da justiça. São Paulo: Ed. Sumaré, 1995.

SHAPIRO, Martin; SWEET, Alec Stone. On Law, Politics, and Judicialization. Oxford: Oxforf Press, 2002. SILVA, Luís Virgílio Afonso da; VEIGA DA ROCHA, Jean Paul. A regulamentação do sistema financeiro nacional: o artigo 192 e o mito da lei complementar única. São Paulo: Revista de Direito Mercantil, Industrial, Econômico e Financeiro, n. 127, 2002.

SOLA, Lourdes; KUGELMAS, Eduardo; WHITEHEAD, Laurence. Orgs. Banco Central, autoridade política e democratização - um equilíbrio delicado. Rio de Janeiro: FGV, 2002.

TATE, C. Neal. Why the expansion of judicial power?. In: TATE, C. Neal; VALLINDER, Torbjörn. Orgs. The global expansion of judicial power. New York: New York University Press, 1995.

When the courts go marching in. In: TATE, C. Neal; VALLINDER, Torbjörn. Orgs. The global expansion of judicial power. New York: New York University Press, 1995.

VEIGA DA ROCHA, Jean Paul. A capacidade normativa de conjuntura no direito econômico: o déficit democrático da regulação financeira. Tese de doutoramento, FDUSP. São Paulo, jun., 2004.

VIANNA, Luis Werneck et al. A judicialização da politica e das relações sociais no Brasil. Rio de Janeiro: Renavan, 1999.

Rua Silvia, 23, cj. 5 Bela Vista - 01331-010 São Paulo - SP - Brasil camila.ferreiralafgv.br
Mestre e doutoranda pela Faculdade de Direito da Universidade de São Paulo (FDUSP)

Coordenadora de Prática Jurídica e Atividades Complementadas da Escola de Direito de São Paulo da Fundação Getulio Vargas (DIREITO GV) 